This work is licensed under a Creative Commons Attribution License (CC BY 4.0).

\title{
A new genus and species of tachinid flies from Iran (Diptera, Tachinidae, Goniini)
}

\section{Ebrahim GILASIAN ${ }^{1, *}$, Joachim ZIEGLER ${ }^{2}$, Andrea TÓTHOVÁ ${ }^{3} \&$ Mehrdad PARCHAMI-ARAGHI ${ }^{4}$}

\footnotetext{
${ }^{1,4}$ Insect Taxonomy Research Department, Iranian Research Institute of Plant Protection (IRIPP), Agricultural Research, Education and Extension Organization (AREEO), Tehran, 19395-1454, Iran.

${ }^{2}$ Museum of Natural History, Leibniz Institute for Research on Evolution and Biodiversity, Invalidenstraße 43, 10115 Berlin, Germany.

${ }^{3}$ Department of Botany and Zoology, Faculty of Science, Masaryk University, Kotlářská 2, 61137 Brno, Czech Republic.

*Corresponding author: ebrahimgilasian@gmail.com, gilasian@iripp.ir

${ }^{2}$ Email: joachim.ziegler@mfn.berlin

32Email: tothova@sci.muni.cz

${ }^{4}$ Email: maraghi20@yahoo.ca

${ }^{1}$ urn:lsid:zoobank.org:author:A45912ED-BEEB-4733-AC6E-C22ACAFD6F63

${ }^{2}$ urn:lsid:zoobank.org:author:6AD804ED-ACB7-4AE5-B495-09A507701BA3

${ }^{3}$ urn:1sid:zoobank.org:author:F748FF06-A0E7-422A-A775-D2494A3A9F60

${ }^{4}$ urn:lsid:zoobank.org:author:5EE45883-3C41-447E-B09A-2B3217C90F00
}

\begin{abstract}
Susamyia Ziegler \& Gilasian gen. nov. and its type species Susamyia mira Ziegler \& Gilasian gen. et sp. nov. are described from southwestern Karkheh National Park and southeastern Jazmourian Wetland of Iran. Drawings of terminalia and head of the male as well as images of habitus, head and egg are provided. Susamyia gen. nov. is incorporated into the identification key to the Palearctic tachinid genera of Tschorsnig \& Richter (1998). The systematic position of Susamyia gen. nov. in the tribe Goniini (Exoristinae) is discussed in light of molecular analyses based on the ribosomal genes 16S, 18S and 28S, and the egg type of females. The morphology of the microtype eggs was studied and compared with that of other Goniini, but proved too unreliable to be included in the phylogenetic analysis. Susamyia gen. nov. is believed to be most closely related to the goniine genera Gymnophryxe Villeneuve, 1922, Palesisa Villeneuve, 1929 and Prosopodopsis Townsend, 1926.
\end{abstract}

Keywords. Exoristinae, identification key, taxonomy, Palearctic.

Gilasian E., Ziegler J., Tóthová A. \& Parchami-Araghi M. 2021. A new genus and species of tachinid flies from Iran (Diptera, Tachinidae, Goniini). European Journal of Taxonomy 746: 162-185.

https://doi.org/10.5852/ejt.2021.746.1331 


\section{Introduction}

Tachinidae are an ecologically important family of parasitoid insects whose Iranian fauna is believed to comprise many surprising records or undescribed species. For example, our current studies just in the Karkheh and Dez National Parks, located in the southwestern province of Khuzestan, have resulted in the discovery of a number of taxa of which three species have already been found to be new to science (Gilasian et al. 2016a, 2016b, 2018, 2019). This research was conducted as part of our ongoing study of the tachinid fauna of Persian Gulf provinces of Iran, including the southeastern Balouchestan region, and intended to improve the existing taxonomic knowledge of Tachinidae in Iran and in the Western Palearctic region. Our findings show that this area is home to many interesting tachinid species, which have strong affinities with other zoogeographical regions. The new species, discovered first in the Karkheh National Park, was found to belong to an undescribed genus as its characters did not correspond with any other tachinid genera. Our preliminary morphological analysis showed that this species would be a member of the largest tachinid subfamily Exoristinae with estimated 3600 species worldwide, which also dominates the other tachinid subfamilies in the Palearctic region, with about 870 recorded species (O'Hara et al. 2020). Compared to the other subfamilies, Exoristinae shows the lowest level of morphological diversity representing good congruence with the results derived from DNA analysis indicating this subfamily as a young and rapidly evolving group of Tachinidae with the eryciine/goniine assemblage at the top (Stireman et al. 2019). Our new genus and species share the characters of the exoristine tribes Goniini and Eryciini, which are morphologically very close to each other; however, the species of Goniini are strikingly different from Eryciini in their oviposition strategy of depositing specialized microtype eggs (Herting 1957). At the outset of this research, the lack of female specimens urged us to employ molecular analyses to reliably determine the position of the new genus. Although the new genus morphologically shares external characters that occur in both tribes Goniini and Eryciini, the results from molecular analyses and later the discovery of the female and its possession of microtype eggs confirm the position of the new genus within Goniini.

\section{Material and methods}

The specimens of the new genus were collected in Karkheh and Dez National Parks with the exception of one female, which belongs to the southeastern Iranian side of the Balouchestan region (Figs 1-2). The Karkheh and Dez National Parks are situated in the southwestern province of Khuzestan, which is part of the Irano-Turanian biogeographic zone. The Khuzestan Plain, which borders Iraq on the west and Persian Gulf on the south, is known for its permanent large rivers whose sediments have created one of the most fertile agricultural lands in Iran. The climate is characterized by an annual precipitation of about 200-300 mm (winter rains), and long, hot and dry summers including high atmospheric humidity. The natural vegetation consists mainly of ephemeral forb communities (Gilasian et al. 2016a, 2018).

In addition to the type series of Susamyia mira Ziegler \& Gilasian gen. et sp. nov., further pinned specimens of goniine and eryciine species from different localities of the Palearctic region have been examined in the course of this study. The material is deposited in the following collections (abbreviations mostly from Evenhuis 2020):

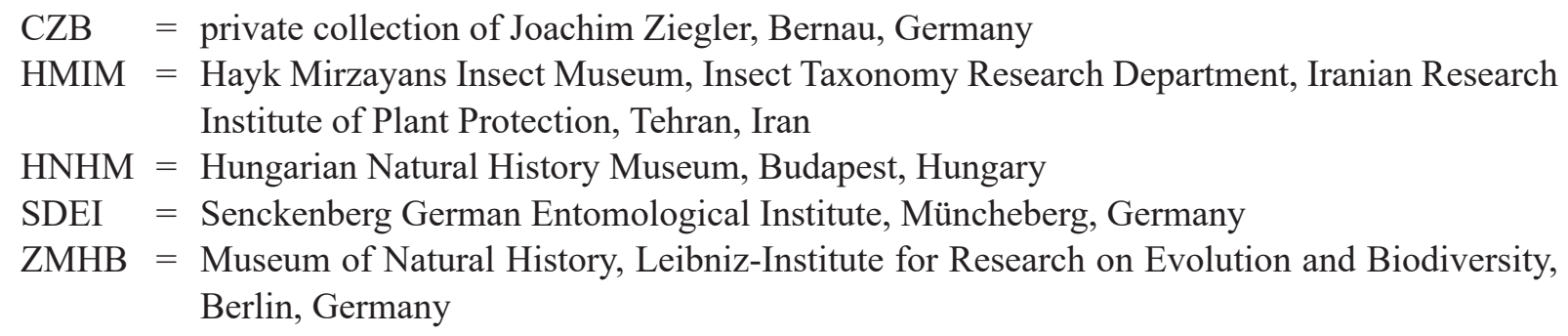
Institute of Plant Protection, Tehran, Iran

HNHM = Hungarian Natural History Museum, Budapest, Hungary

SDEI = Senckenberg German Entomological Institute, Müncheberg, Germany

ZMHB = Museum of Natural History, Leibniz-Institute for Research on Evolution and Biodiversity, Berlin, Germany 


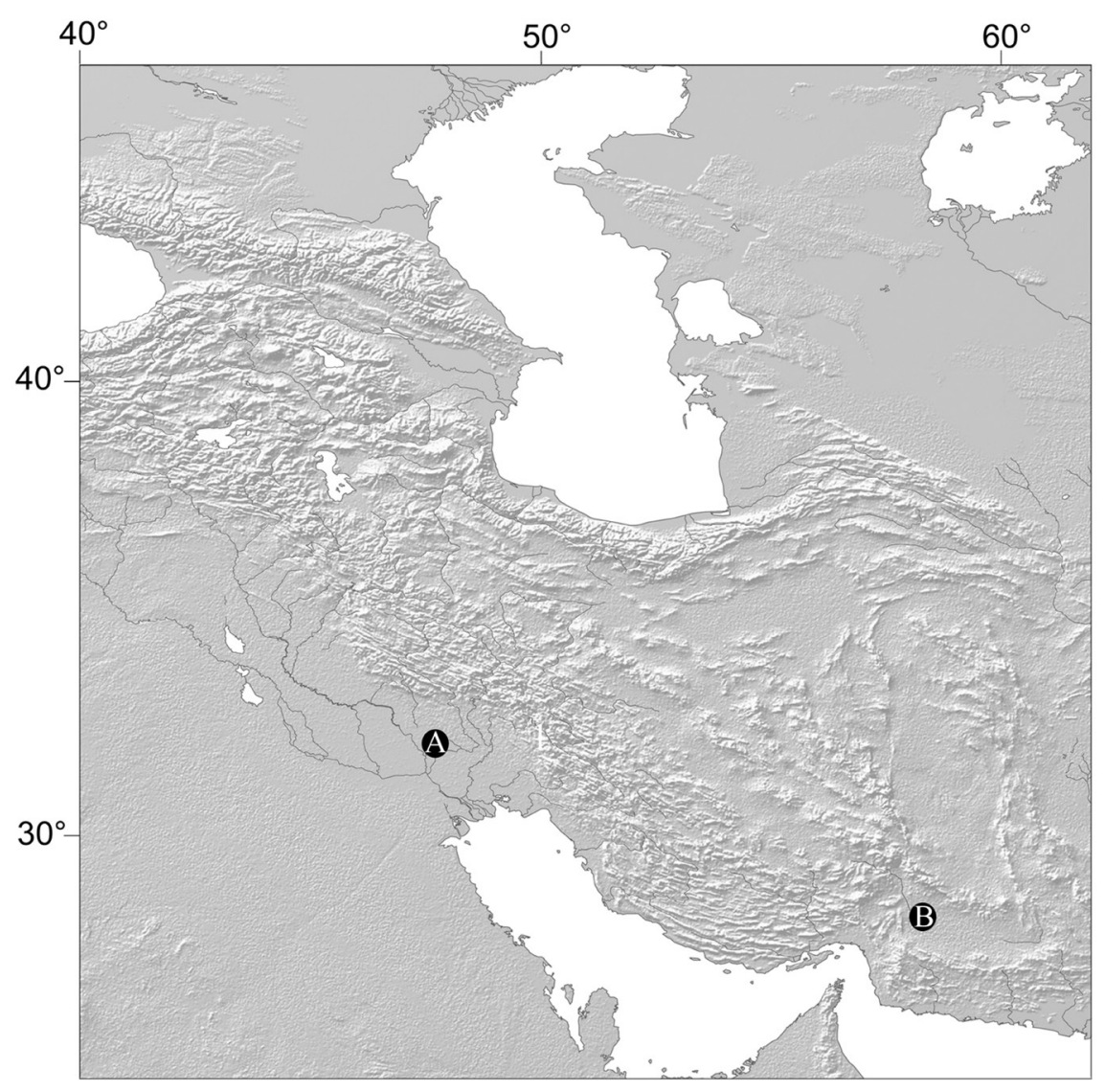

Fig. 1. Distribution of Susamyia mira Ziegler \& Gilasian gen. et sp. nov. in Iran. A. Karkheh and Dez National Parks. B. Dalgan.

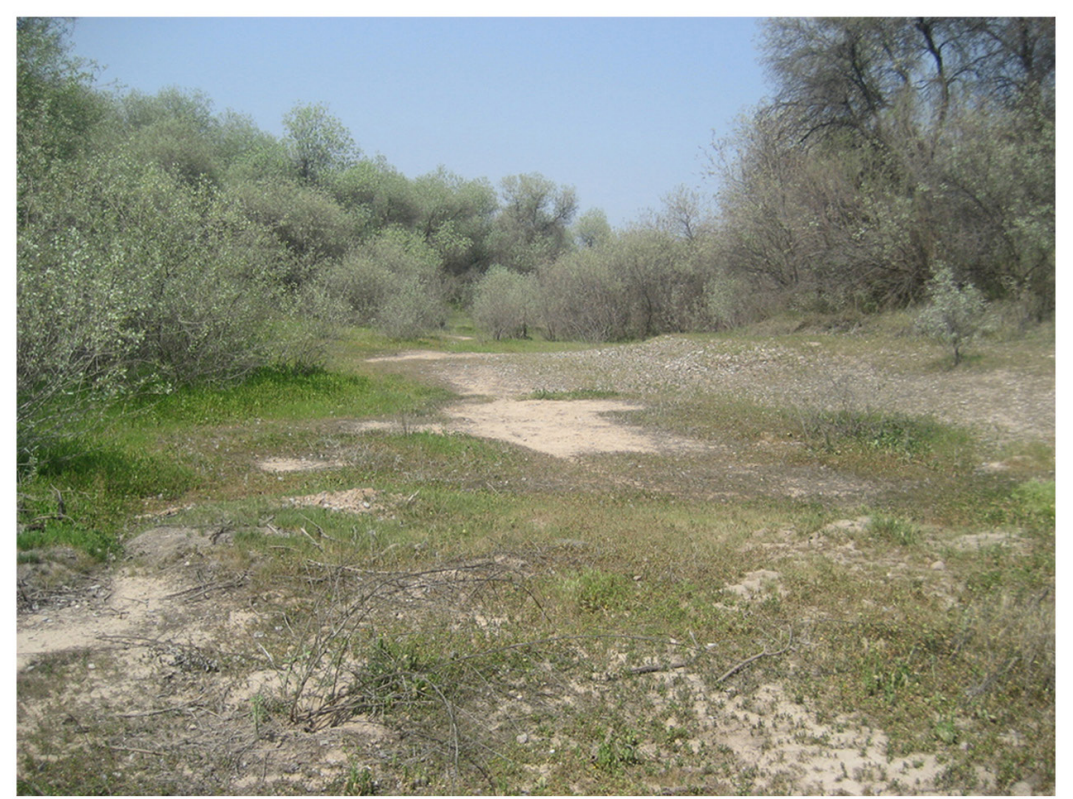

Fig. 2. Habitat of Susamyia mira Ziegler \& Gilasian gen. et sp. nov. in the Karkheh National Park, Khuzestan Province, Iran. 
GILASIAN E. et al., Susamyia mira, a new tachinid genus and species from Iran

All specimens of the new genus were captured directly in $75 \%$ ethanol containers of the Malaise traps (see Gilasian et al. 2016a: fig. 2). To prepare some specimens from ethanol, we followed the AXA method proposed by van Achterberg (2009) to avoid shrinkage of the specimens before pinning (a single female specimen was glued). An Olympus SZH stereo microscope, equipped with a drawing tube, was used for preparing the drawings of head and male terminalia. Inked drawings were edited using Adobe Photoshop CS2. The preparation of the male terminalia was carried out according to the methods outlined in Gilasian et al. (2016b).

Digital images of the flies were taken by JZ through a Multifocus-Station Leica consisting of a Z16Apo stereo microscope and a DFC 495 digital camera operated by Leica Application Suite 4.5; Helicon Focus 6 was used for stacking the serial images. To extract the eggs, we detached the female abdomen and left it overnight in potassium hydroxide $10 \%$ at room temperature. Afterward, the mass of microtype eggs was removed from the abdomen and transferred into glycerin. The digital images of eggs were taken by JZ using a microscope Axioplan 2 with AxioCam MRc5 being equipped with the objectives Neofluar $40 \times 0.75$ and Plan-Apochromat $63 \times 1.40$.

Measurements and ratios were calculated as proposed by Tschorsnig \& Herting (1994) and Tschorsnig \& Richter (1998). Statements given in square brackets in the description refer to paratypes. Overall lengths of specimens (in $\mathrm{mm}$ ) were measured in lateral view from the anterior margin of the head, excluding the antenna, to the tip of the abdomen. The label data of specimens are given verbatim, with a forward slash separating different lines, a double forward slash separating different labels and descriptive information included in square brackets. The morphological terminology used in this paper follows Merz \& Haenni (2000) (most external morphology), Stuckenberg (1999) (antenna), Sinclair (2000) (male terminalia) and Tschorsnig \& Richter (1998) (wing).

\section{DNA extraction, PCR and sequencing}

DNA was extracted from the ethanol-preserved adult flies using the DNeasy Blood \& Tissue Kit (QIAGEN) following the manufacturer's protocol. Individual flies or tissue portions were rinsed in PBS, placed in sterile Eppendorf tubes and, after adding proteinase K, samples were incubated overnight at $56^{\circ} \mathrm{C}$. PCRs (total volume $=20 \mu \mathrm{l}$ ) were performed using primers published in Roháček et al. (2009) (ribosomal 16S). Two nuclear genes, ribosomal $18 \mathrm{~S}$ and $28 \mathrm{~S}$, were amplified using primers according to Katana et al. (2001) and Belshaw et al. (2001), respectively. Amplified products were purified using the QIAquick PCR Purification Kit (QIAGEN). Sequencing in both directions was carried out with BigDye Terminator ver. 3.1 (Applied Biosystems) on an ABI 3100 genetic sequencer (Perkin Elmer Applied Biosystems). All sequences were assembled and edited in SEQUENCHER ver. 4.8 (Gene Codes Corporation). GenBank accession numbers for the sequences are listed in Table 1.

\section{Alignment and phylogenetic analyses}

For the phylogenetic reconstructions and the most precise positioning of new genus Susamyia Ziegler \& Gilasian gen. nov., we used the data available in GenBank based on the previous study of Tachi \& Shima (2010). The data of the new genus were obtained during this study. The sequences were aligned using MAFFT ver. 7 (Katoh \& Standley 2013) on the MAFFT server (http://mafft.cbrc.jp/alignment/server/). The final dataset consisted of 28 specimens as terminal 'taxa' and 3486 DNA characters: $16 \mathrm{~S}-407 \mathrm{bp}$, $18 \mathrm{~S}-1798$ and $28 \mathrm{~S}-1281 \mathrm{bp}$.

To evaluate the best-fit model for the Bayesian inference (BI) and maximum likelihood (ML) analyses, the concatenated data set was partitioned into three sets, representing the three gene regions $(16 \mathrm{~S}, 18 \mathrm{~S}$ and 28S). Each DNA partition was evaluated in MrModeltest ver. 2.2 (Nylander 2004) using both hierarchical likelihood ratio tests (hLRTs) and Akaike information criterion (AIC). The model GTR + $\mathrm{I}+\mathrm{G}$ was chosen as the best-fitting model for all the partitions. 
Table 1. List of GenBank access numbers of analyzed gene fragments which were partly used in the study by Tachi \& Shima (2010).

\begin{tabular}{|c|c|c|c|c|}
\hline Taxa & Group & 16S rDNA & 18S rDNA & 28S rDNA \\
\hline Dinera takanoi (Mesnil, 1957) & Dexiinae & AB465958 & AB466031 & AB466104 \\
\hline Ectophasia rotundiventris (Loew, 1858) & Phasiinae & AB465961 & AB466034 & AB466107 \\
\hline Tachina iota Chao \& Arnaud, 1993 & Tachininae & AB465955 & AB466028 & AB466101 \\
\hline Blondelia nigripes (Fallén, 1810) & Blondeliini & AB465902 & AB465970 & AB466043 \\
\hline Meigenia majuscula (Rondani, 1859) & Blondeliini & AB465909 & AB465977 & AB466050 \\
\hline Aplomya confinis (Fallén, 1820) & Eryciini & AB465916 & AB465984 & AB466057 \\
\hline Carcelia sp. & Eryciini & AB465917 & AB465985 & AB466058 \\
\hline Epicampocera succincta (Meigen, 1824) & Eryciini & AB465918 & AB465986 & AB466059 \\
\hline Isosturmia japonica (Mesnil, 1957) & Eryciini & AB465919 & AB465987 & AB466060 \\
\hline Phebellia glauca (Meigen, 1824) & Eryciini & AB465920 & AB465988 & AB466061 \\
\hline Phryxe heraclei (Meigen, 1824) & Eryciini & AB465921 & AB465989 & AB466062 \\
\hline $\begin{array}{l}\text { Prooppia nigripalpis (Robineau-Desvoidy, } \\
\text { 1848) }\end{array}$ & Eryciini & AB465922 & AB465990 & AB466063 \\
\hline $\begin{array}{l}\text { Senometopia cariniforceps (Chao \& Liang, } \\
\text { 2002) }\end{array}$ & Eryciini & AB465923 & AB465991 & AB466064 \\
\hline Blepharipa sugens (Wiedemann, 1830) & Goniini & AB465932 & AB466004 & AB466077 \\
\hline Botria japonica Mesnil, 1957 & Goniini & AB465933 & AB466005 & AB466078 \\
\hline Calozenillia tamara (Portschinsky, 1884) & Goniini & AB465934 & AB466006 & AB466079 \\
\hline Eumea linearicornis (Zetterstedt, 1844) & Goniini & AB465935 & AB466007 & AB466080 \\
\hline Frontina laeta (Meigen, 1824) & Goniini & AB465936 & AB466008 & AB466081 \\
\hline Gonia chinensis Wiedemann, 1824 & Goniini & AB465937 & AB466009 & AB466082 \\
\hline Nealsomyia rufella (Bezzi, 1925) & Goniini & AB465938 & AB466010 & AB466083 \\
\hline Pales pavida (Meigen, 1824) & Goniini & AB465939 & AB466011 & AB466084 \\
\hline Pexopsis pilosa Mesnil, 1957 & Goniini & AB465940 & AB466012 & AB466085 \\
\hline Phryno katoi Mesnil, 1963 & Goniini & AB465941 & AB466013 & AB466086 \\
\hline Pseudogonia rufifrons (Wiedemann, 1830) & Goniini & AB465942 & AB466014 & AB466087 \\
\hline Sturmia bella (Meigen, 1824) & Goniini & AB465943 & AB466015 & AB466088 \\
\hline Suensonomyia nudinerva Mesnil, 1957 & Goniini & AB465944 & AB466016 & AB466089 \\
\hline $\begin{array}{l}\text { Susamyia mira Ziegler \& Gilasian } \\
\text { gen. et sp. nov. }\end{array}$ & Goniini & MN999942 & MN999945 & MN999944 \\
\hline Zenillia dolosa (Meigen, 1824) & Goniini & AB465945 & AB466017 & AB466090 \\
\hline
\end{tabular}

The partitioned Bayesian inference of 15 million generations on the concatenated data set was implemented in MrBayes ver. 3.2.6 (Huelsenbeck \& Ronquist 2001) and carried out on the CIPRES (CyberInfrastructure for Phylogenetic RESearch) computer cluster, San Diego Supercomputing Center (Miller et al. 2010) with nucmodel $=4$ by 4 , ngen $=15 \mathrm{mil}$, samplefreq $=1000$, nruns $=2$, and nchains $=$ 4. Burn-in was set to $30 \%$. All parameters were unlinked across partitions. The convergence of the runs was assessed by checking the potential scale reduction factor (PSRF) values of each parameter (in all cases, 1.000) and the standard deviation of split frequencies $(<0.002)$ in MrBayes. The ML analysis was conducted in Garli ver. 2.0 with the above mentioned substitution model GTR + I + G (Zwickl 2006). 
Two independent runs of 5 million generations using the default automated stopping criterion were carried out. Nodal support was assessed using a nonparametric bootstrap with 500 replicates. Trees were rooted by the outgroup taxon Dinera takanoi (Mesnil, 1957), and the resulting tree was edited using iTOL (Letunić \& Bork 2016). The node support values are given with the posterior probability (PP) and/or the bootstrap value (BV) appearing below nodes in the relevant trees (Fig. 9).

\title{
Results
}

\section{Taxonomy}

\author{
Class Insecta Linnaeus, 1758 \\ Order Diptera Linnaeus, 1758 \\ Family Tachinidae Robineau-Desvoidy, 1830 \\ Subfamily Exoristinae Robineau-Desvoidy, 1863 \\ Tribe Goniini Robineau-Desvoidy, 1830 sensu Herting, 1957 \\ Genus Susamyia Ziegler \& Gilasian gen. nov. \\ urn:lsid:zoobank.org:act:D91AA3EC-2302-46C5-B269-F6B5BFD300AB
}

Type species: Susamyia mira Ziegler \& Gilasian gen. et sp. nov.

\section{Etymology}

The first part of the genus name 'Susamyia' (Latin, substantive feminine) refers to the historical name of the city of Susa, pronounced 'Shoush' in modern Persian, and permanently inhabited for 6200 years. The city is located in the southwestern Khuzestan Province of Iran, between the Karkheh and Dez Rivers, where the holotype was collected. The second part of the name is the Greek word 'myia', which means 'fly'.

\section{Description}

Eye bare; gena with black setulae; height of gena in lateral view about 0.2 times as long as vertical diameter of eye; face 1.2-1.3 times as long as frons; frons at its narrowest point wider than an eye, at most 1.3 times as wide as an eye viewed dorsally; upper part of head without black setulae behind the postocular row; facial ridge with erect setae; parafacial bare, moderately narrow; fronto-orbital plate with 2 proclinate orbital setae and usually a single reclinate upper orbital seta, if two present, then uppermost stronger; postpedicel not pointed dorsoapically, much longer than pedicel; arista almost bare, thickened in basal $3 / 5$; first and second aristomeres short; prosternum setose; proepisternum bare; 3 strong basal setae of postpronotum arranged in a nearly straight line; scutum with 4 postsutural dorsocentral setae; first postsutural supra-alar seta longer than notopleural setae; mesopleuron with black setulae; postmetacoxal area membranous; scutellum with 4 pairs of marginal setae; apical setae of scutellum at most inclined at $30^{\circ}$ to horizontal; lateral scutellar setae strong and as long as basal setae; katepisternum with 3 setae almost in a line; lower calypter not exceptionally convex at outer margin; vein $\mathrm{R}_{4+5}$ setose at most halfway to crossvein $\mathrm{r}-\mathrm{m}$; wing cell $\mathrm{r}_{4+5}$ open or closed at wing margin; section of vein $\mathrm{M}$ between crossveins $\mathrm{r}-\mathrm{m}$ and $\mathrm{dm}-\mathrm{cu}$ distinctly longer than section between $\mathrm{dm}-\mathrm{cu}$ and bend of $\mathrm{M}$; bend of $\mathrm{M}$ forming a right angle; vein $\mathrm{M}$ complete; bend of vein $\mathrm{M}$ flat, without continuation; crossvein $\mathrm{dm}$-cu not exceptionally oblique; preapical anterodorsal seta on fore tibia shorter than preapical dorsal seta; mid tibia with a nearly complete row of different-sized anterodorsal setae; hind coxa bare posterodorsally; hind tibia with 2 preapical dorsal setae; preapical posteroventral seta on hind tibia shorter than preapical anteroventral seta; abdomen predominantly covered with dense grey microtrichosity; middorsal depression of syntergite $1+2$ extending back to posterior margin of that segment; tergites 3-4 without median discal setae. 
Susamyia mira Ziegler \& Gilasian gen. et sp. nov. urn:lsid:zoobank.org:act:7F3A2907-E8D8-46A9-9650-DAD0F7E01ADB

Figs 3-4, 5A-B, 6A, C-E, 7, 8A, C-D

\section{Etymology}

The species name 'mira' (Latin, adjective) is derived from 'mirus' (amazing, astonishing, surprising).

\section{Material examined}

\section{Holotype}

IRAN • $\widehat{O}$ (pinned); IRAN: Khuzestan prov., / Shoush, Karkheh National / Park, Persian Fallow Deer / Sanctuary, 32 $04^{\prime} 30.1^{\prime \prime} \mathrm{N} / 48^{\circ} 14^{\prime} 24.2^{\prime \prime} \mathrm{E}$, June 28-July 4 / 2013, 66m, Malaise trap, M. / ParchamiAraghi // HOLOTYPUS § / Susamyia mira / Ziegler \& Gilasian / 2021 [red label]; HMIM.

\section{Paratypes}

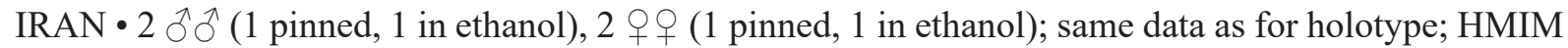
- $1 \partial^{\Uparrow}$ (pinned); same data as for holotype except $32^{\circ} 04^{\prime} 42.2^{\prime \prime} \mathrm{N} / 48^{\circ} 14^{\prime} 34.8^{\prime \prime} \mathrm{E}$, near swamp, / May 13June 14 2014, 63 m, / Malaise trap, M. Parchami- / Araghi leg.; SDEI • 1 ô, 1 q (pinned); same data as for holotype except $32^{\circ} 04^{\prime} 45.6^{\prime \prime} \mathrm{N} 48^{\circ} 14^{\prime} 27.8^{\prime \prime} \mathrm{E} / 10$.V.-10.VII. 2015, $68 \mathrm{~m} /$ leg. Gilasian; ZMHB - 1 ऽ (pinned); same data as for holotype except Dez National Park, Mianrood, / Persian Fallow Deer Sanctuary, / 32 $06^{\prime} 23.5^{\prime \prime} \mathrm{N} / 48^{\circ} 26^{\prime} 17.2^{\prime \prime} \mathrm{E}$, near marsh, / May 13-June 14 2014, $54 \mathrm{~m}$, / Malaise trap, M. Parchami- / Araghi leg.; HMIM 1 9 (glued to a card point); IRAN: Sistan \& Balouchestan prov., / Dalgan, vicinity of / Jolgeh, Chah Hashem, palm / grove, $27^{\circ} 06^{\prime} 08.3^{\prime \prime} \mathrm{N} / 59^{\circ} 07^{\prime} 11.3^{\prime \prime} \mathrm{E}, / 28$ April-2 May 2017, 388 m, Malaise / trap, M. Parchami-Araghi leg.; HMIM.

Each paratype has an additional yellow label containing "PARATYPUS $\widehat{\sigma}$ [or $\$$ ] / Susamyia mira / Ziegler \& Gilasian / 2021".

\section{Additional studied material}

IRAN • $1 \partial^{\lambda}$; same data as for holotype except $32^{\circ} 04^{\prime} 45.6^{\prime \prime} \mathrm{N} 48^{\circ} 14^{\prime} 27.8^{\prime \prime} \mathrm{E} / 10 . \mathrm{V} .-10 . \mathrm{VII} .2015,68 \mathrm{~m}$ $/$ leg. Gilasian; CZB.

Specimen dissected. Head (Fig. 6C-E), postabdomen and left wing prepared separately, the other parts of the body have been destroyed during DNA extraction.

\section{Description}

Male (Figs 3-4, 5A-B, 6A, C-E)

Statements given within square brackets refer to paratypes. Overall length: $6.3-[7.5] \mathrm{mm}$.

COLORATION AND MICROTRICHOSITY. Head predominantly brown; genal setulae black; frontal vitta and lunule light brown; face, parafacial, fronto-orbital plate, gena, genal dilation, ocellar triangle and occiput covered with dense silvery white microtrichosity; occiput with white setulae; scape, pedicel and basal margin of postpedicel orange, other parts of antenna including arista dark brown to black; prementum dark brown; palpus yellow; thorax black, predominantly covered with whitish-grey microtrichosity; presutural portion of scutum with 2 narrow dark median and 2 semi-triangular lateral vittae (seen from behind), posterior margin of postpronotum orange, postsutural portion of scutum orange laterally; scutellum entirely yellowish-orange or (rarely) darker in basal portion, covered with grey microtrichosity; wing hyaline; calypters white; tegula brownish-orange, basicosta pale yellow; halter orange; coxae, femora and tarsi brownish-black, apical half of femora orange ventrally, tibiae dark brownish-orange; abdomen dorsally and ventrally predominantly covered with dense grey microtrichosity on its whole length, without black bands posteriorly, but with black shining spots at base of every seta; syntergite $1+2$ mostly black, posterior half of lateral and ventral portions orange; tergites 3-4 predominantly orange, 
each with a dorsal black trapezoidal spot; tergite 5 orange with a semi triangular black spot dorsally; margins of all tergites pale yellow; sternites black; postabdomen mostly orange.

HEAD (Figs 3, 6C-E). Eye bare; height of gena in lateral view [0.17]-0.21 times as long as vertical diameter of eye; face [1.20]-1.27 times as long as frons in lateral view; frons at its narrowest point $1.15-1.39$ [1.30] times as wide as an eye viewed dorsally; frontal vitta nearly as wide as fronto-orbital plate medially; medial vertical setae almost $0.65-[0.72]$ times as long as vertical diameter of eye, lateral vertical setae 0.50-[0.59] times as long as medial (inner) vertical setae; ocellar setae proclinate or [lateroreclinate]; postocellar setae parallel and [0.57]-0.75 times as long as lateral vertical setae; upper part of head without black setulae behind the postocular row; frons with 4-[6] frontal setae descending to level of lower margin of pedicel; the uppermost seta sometimes reclinate, as if upper orbital seta; facial ridge with erect setae on lower $2 / 3-[3 / 4]$, parafacial bare, at its narrowest point [0.18]-0.21 times as wide as transverse eye diameter and almost [0.60]-0.70 times as wide as postpedicel in lateral view; fronto-orbital plate with a few scattered setulae; 2 proclinate orbital and 1 reclinate upper orbital setae (Fig. 6A), sometimes preceding a weaker reclinate upper frontal or orbital seta (Fig. 3); fronto-orbital plate at level of scape 0.30-[0.37] times as wide as the transverse diameter of eye; vibrissa arising at level of lower facial margin and $0.70-[0.75]$ times as long as face; lower facial margin not visible in lateral view; postpedicel about 6.8 [6.5-7.5] times as long as pedicel and 4.1-[4.2] times as long as

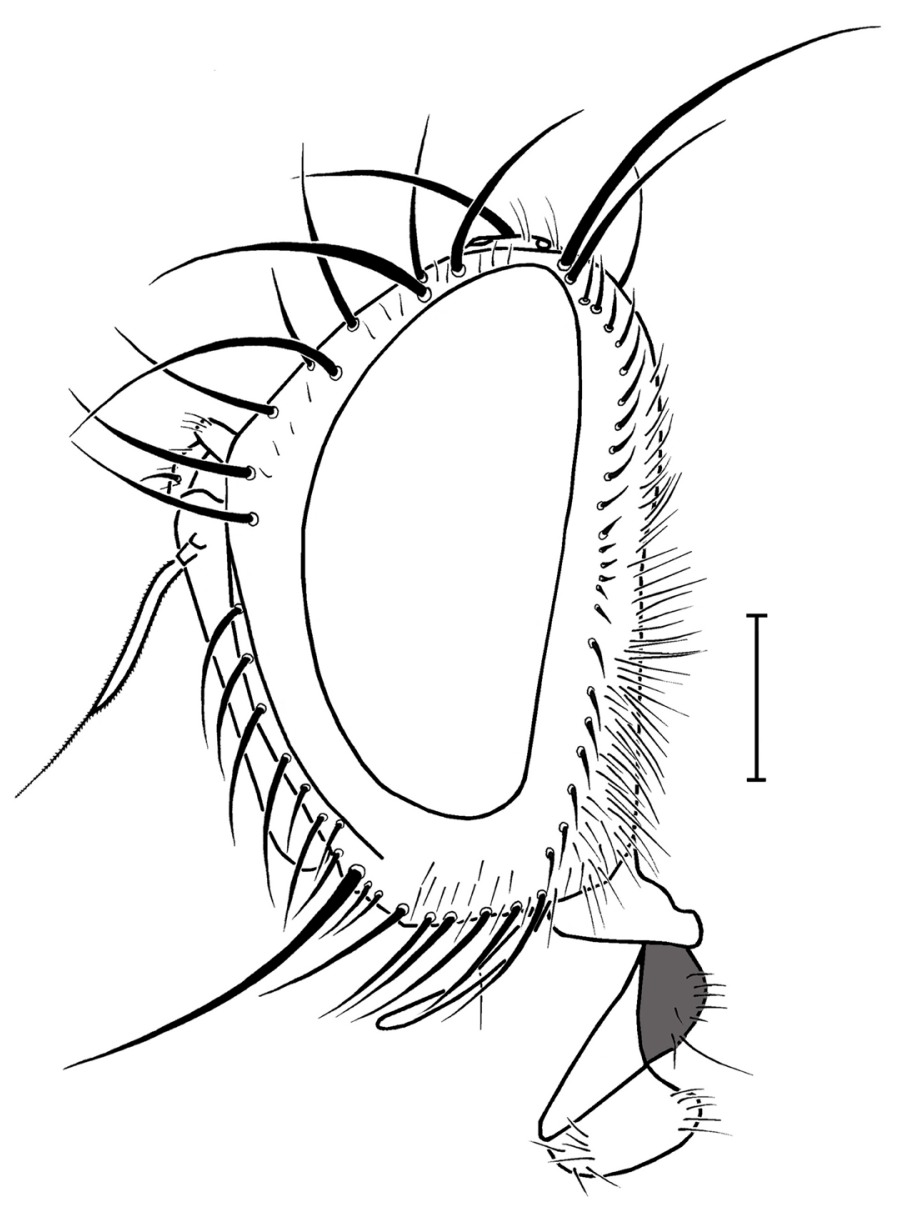

Fig. 3. Susamyia mira Ziegler \& Gilasian gen. et sp. nov., holotype, ô (HMIM); head in lateral view. Scale bar $=0.5 \mathrm{~mm}$. 
wide; arista thickened in basal 3/5, first aristomere shorter than wide; second aristomere [2.0]-2.5 times as long as first aristomere, $1.2-1.8$ times as long as wide; prementum very short; palpus slender and cylindrical, with only a few setulae.

Thorax. Prosternum setose; proepisternum bare; postpronotum with 3-4 setae, 3 strong basal setae arranged in a nearly straight line, often an additional distal weak seta between middle and basal setae; scutum with $3+3$ acrostichal, $3+4$ dorsocentral, 1+3 intra-alar, 2 notopleural, 3 supra-alar setae; first postsutural supra-alar seta longer than notopleural setae and longer than first postsutural intra-alar seta; postalar callus with 2 setae; anatergite bare below calypter; katepimeron bare; katepisternum with 3 setae almost in a line; postmetacoxal area membranous; scutellum with 4 pairs of marginal setae, apical setae

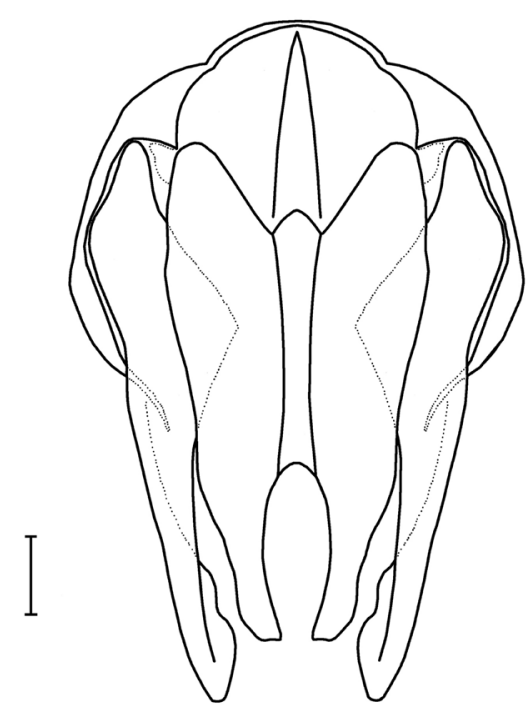

A

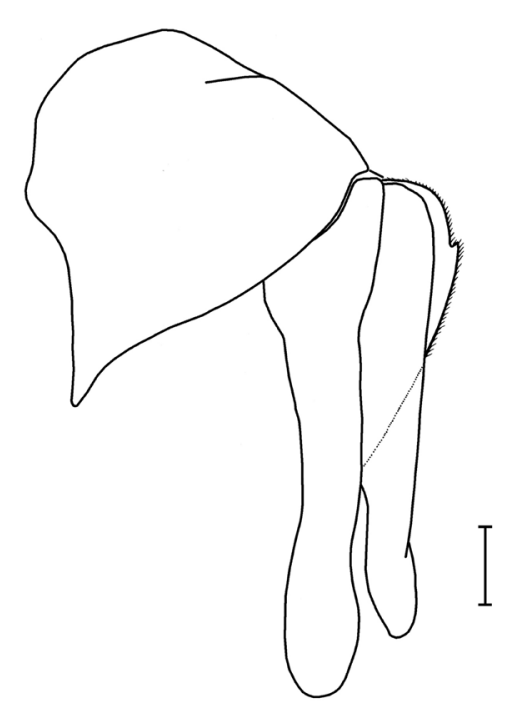

$\mathrm{B}$
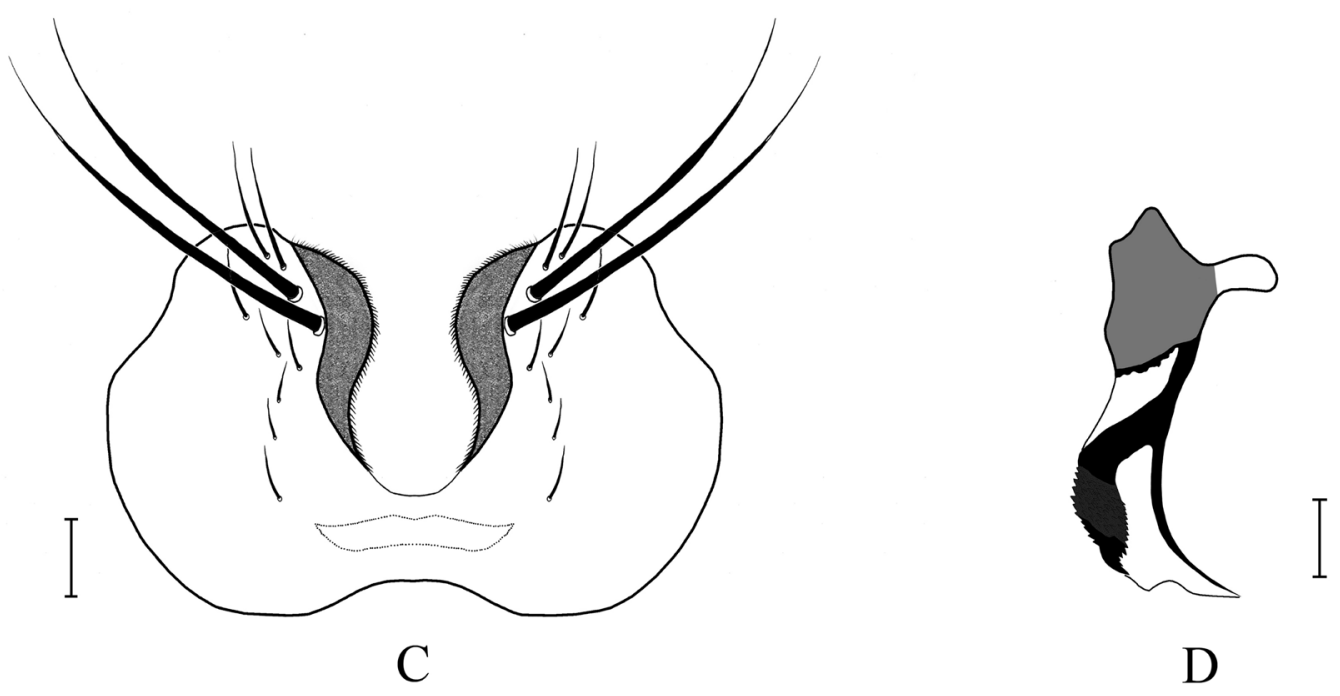

$\mathrm{D}$

Fig. 4. Susamyia mira Ziegler \& Gilasian gen. et sp. nov., paratype, $\widehat{\partial}$ (HMIM); terminalia. A. Epandrium, cerci and surstyli, dorsal view. B. Epandrium, cerci and surstyli, lateral view. C. Sternite 5. D. Aedeagus, lateral view. Scale bars $=0.1 \mathrm{~mm}$. 
weak, crossed and horizontal or [inclined at most at $30^{\circ}$ to horizontal], lateral setae strong and as long as basal setae; subapical setae usually longer and stronger than other scutellar setae; dorsal surface of scutellum covered with erect setulae and with 1 pair of inclined discal setae on apical 1/3.

WING. Second costal section bare ventrally; costal seta nearly as long as crossvein r-m; fourth costal section (between $\mathrm{R}_{2+3}$ and $\mathrm{R}_{4+5}$ ) approximately as long as second costal section (between subcostal break and $\mathrm{R}_{1}$ ); third costal section 1.8-[2.0] times as long as fourth costal section; vein $\mathrm{R}_{4+5}$ with 3-[5] basal setulae dorsally and 2-[4] basal setulae ventrally; wing cell $\mathrm{r}_{4+5}$ narrowly open or [closed at wing margin]; section of vein $\mathrm{M}$ between crossveins $\mathrm{r}-\mathrm{m}$ and $\mathrm{dm}-\mathrm{cu}$ [2.3]-2.5 times as long as section between $\mathrm{dm}-\mathrm{cu}$ and bend of $\mathrm{M}$; bend of $\mathrm{M}$ forming a right angle without appendix; crossvein dm-cu 5.0-[5.5] times as long as crossvein $\mathrm{r}-\mathrm{m}$.

Legs. Fore leg. Tibia with 2 posterior setae and a complete row of anterodorsal and posterodorsal setae; preapical anterodorsal seta shorter than preapical dorsal seta; tarsomere 1 nearly 2.1 times as long as tarsomere 2 and 0.4 times as long as tibia; claws short, 0.4 times as long as tarsomere 5. Mid leg. Tibia with a nearly complete row of different-sized anterodorsal setae, of which 2-3 setae very strong and long; 2-[3] posterior and [1]-2 ventral setae. Hind leg. Coxa bare on anterior and posterior surfaces; tibia with a complete row of anterodorsal setae of irregular size, 3-[5] posterodorsal, 2-[3] ventral setae, 2 preapical dorsal setae; preapical posteroventral seta shorter than preapical anteroventral seta.

ABdomen. Middorsal depression of syntergite $1+2$ extending back to posterior margin of segment; syntergite $1+2$ and tergite 3 each with 1 pair of median marginal and 1 pair of lateral marginal setae; tergites 3-4 with depressed setulae dorsally, without median discal setae; tergite 30.45 times as long as wide; tergites $4-5$ each with a complete row of marginal setae, tergite 5 with erect discal setae dorsally and 0.65 times as long as tergite 4 .

Postabdomen (Fig. 4). Sternite 5 with a deep median apical depression, without sensilla trichodea (Fig. 4C); membrane binding between sternite 6 and segment 7 very narrow; epandrium 2.3 times as long as syntergite 6-8; cercus convex in the middle of basal part and depressed downwards in the middle of apical part (Fig. 4A); cercus and surstylus narrow in lateral view, surstylus longer than cercus (Fig. 4B); aedeagus as in fig. 4D.

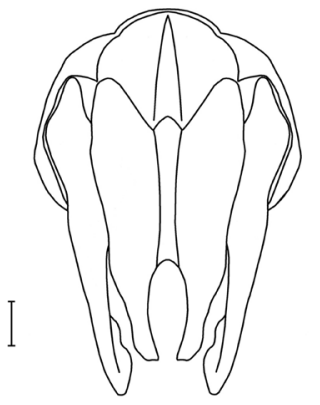

A

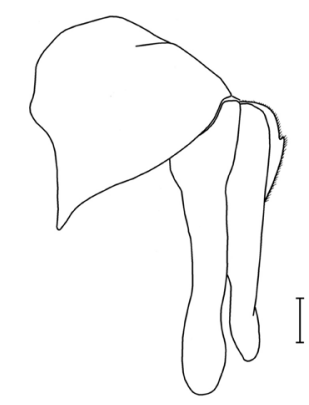

$\mathrm{B}$

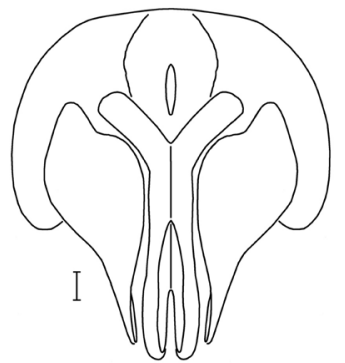

$\mathrm{C}$

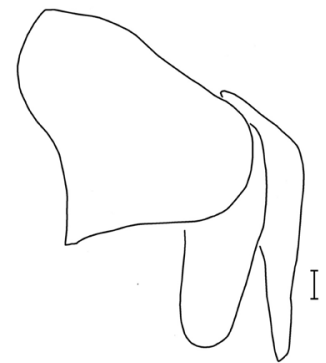

$\mathrm{D}$

Fig. 5. Characters of male terminalia: epandrium, cerci and surstyli. A-B. Susamyia mira Ziegler \& Gilasian gen. et sp. nov., paratype, ठ̊ (HMIM). A. Dorsal view. B. Lateral view. C-D. Gymnophryxe theodori (Kugler, 1968), $\hat{\sigma}^{\lambda}$ (CZB). C. Dorsal view. D. Lateral view. Scale bars $=0.1 \mathrm{~mm}$. 


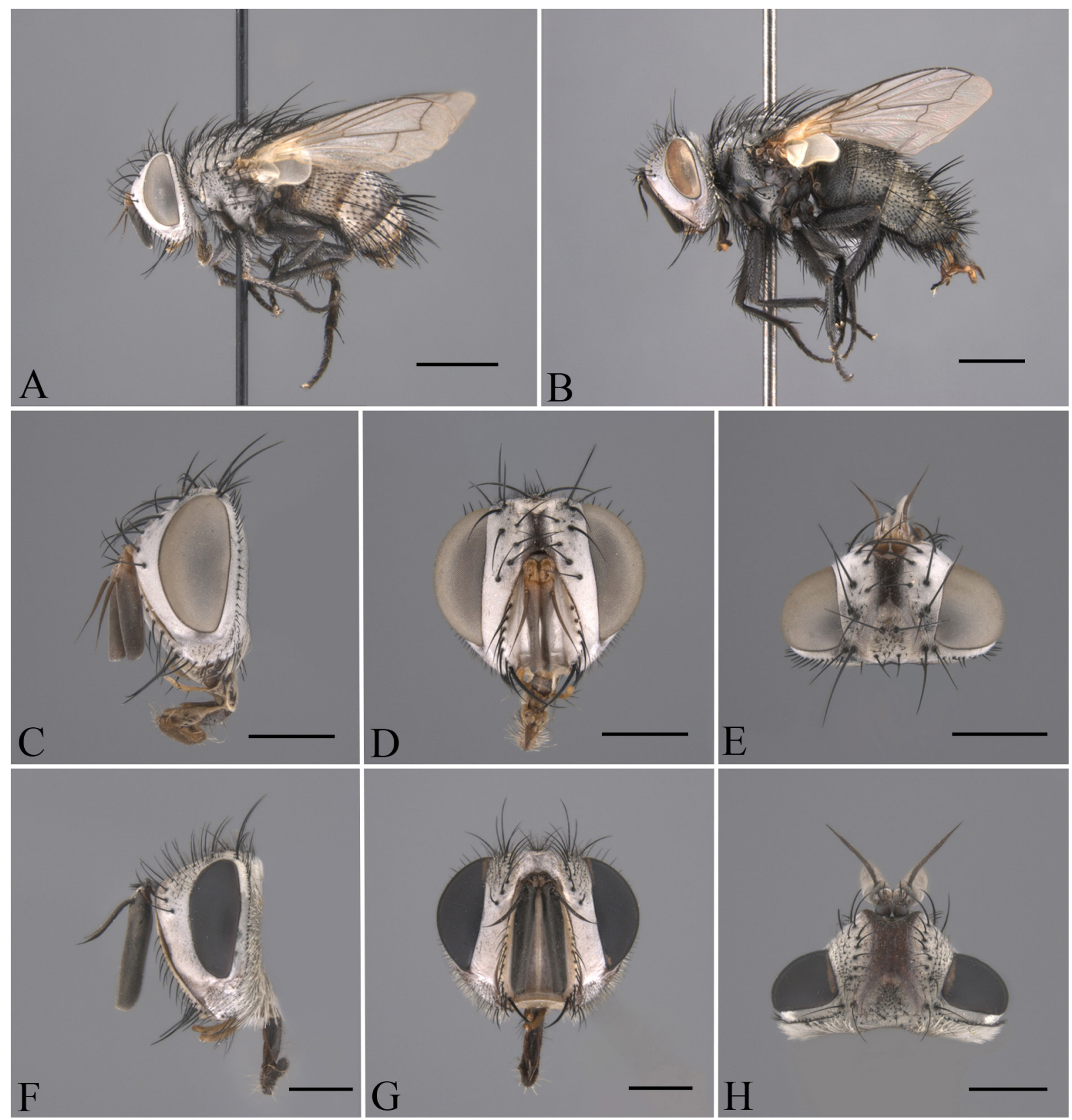

Fig. 6. Characters of Susamyia mira Ziegler \& Gilasian gen. et sp. nov. and Gymnophryxe theodori

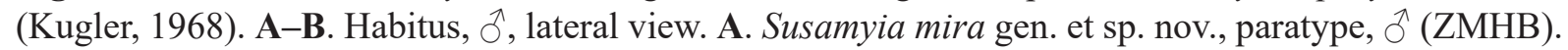
B. Gymnophryxe theodori, $\widehat{\jmath}(\mathrm{CZB})$. C-H. Male head. C-E. Susamyia mira gen. et sp. nov., $\widehat{\partial}(\mathrm{CZB})$. C. Lateral view. D. Frontal view. E. Dorsal view. F-H. Gymnophryxe theodori, ô (CZB). F. Lateral view. G. Frontal view. H. Dorsal view. Scale bars: A-B $=2.0 \mathrm{~mm}$; $\mathrm{C}-\mathrm{H}=1.0 \mathrm{~mm}$. 


\section{Female}

Differs from male by combination of the following characters: facial ridge with only 3-4 erect and spaced setae on nearly lower $1 / 2$; ocellar triangle and frontal vitta orange; postpedicel narrower and shorter, about 4.5-5.4 times as long as pedicel; trapezoidal black spots on abdominal tergites 3-4 much smaller; dorsal black spot on tergite 5 very small; margins of all tergites orange.

EGG (Fig. 7). Microtype, oval, planoconvex (lenticular), maximum diameter 0.18-0.23 mm, embryonated. Dorsal chorion thick, dark brown, with fine sculpture (Fig. 7A); seen from ventral semi-transparent (Fig. 7B).
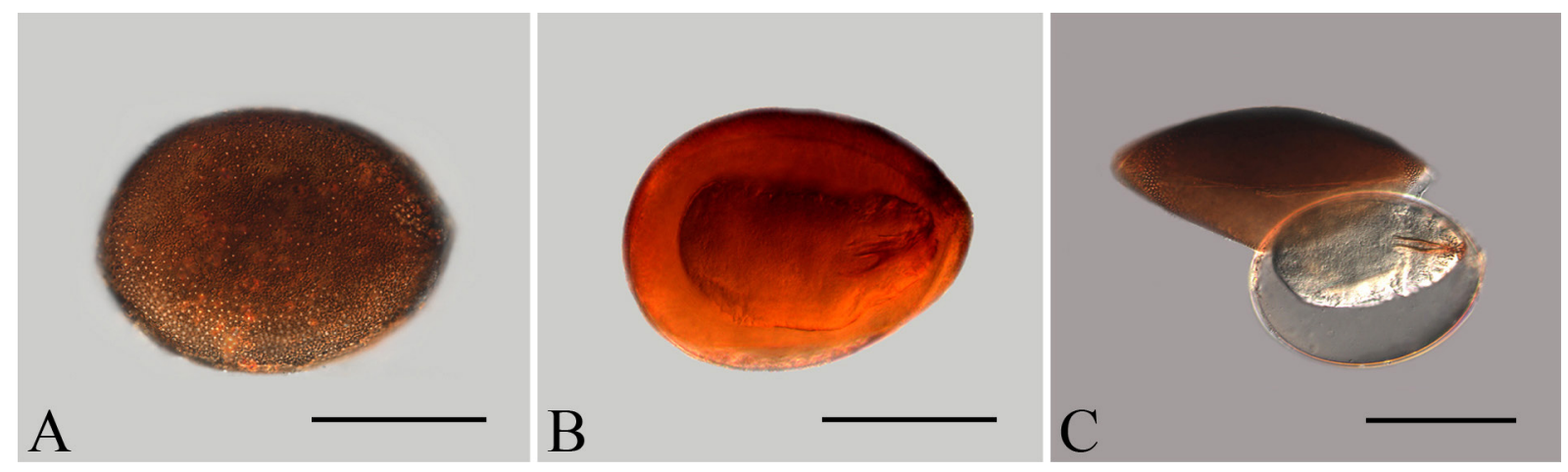

Fig. 7. Susamyia mira Ziegler \& Gilasian gen. et sp. nov.; egg. A. Dorsal view. B. Ventral view. C. Lateral view after light maceration. The egg lost the connection with the dorsal chorion. Inside the egg is the larva (ready to hatch). Scale bars $=0.1 \mathrm{~mm}$.

\section{Additional material selected for detailed comparisons (other species)}

\section{Holotype}

Gymnophryxe modesta Herting, 1973

MONGOLIA - 0 , damaged; with three printed white labels: "MONGOLIA, Central aimak / UlanBaator, Nucht im / Bogdo ul, 1880 m / Exp. Dr. Z. KAZAB, 1966 // Nr. 507 / 9.VI.1966 // Gymnophryxe / modesta n. sp. [handwritten by Herting] / B. Herting det. [printed]", with red label: "TYPUS [printed] / Gymnophryxe / modesta / Herting [handwritten by Herting]"; HNHM.

\section{Gymnophryxe inconspicua (Villeneuve, 1924)}

KYRGYZSTAN • 1 o; ; with two printed white labels: "KYRGYZSTAN, Talas Oblast / Tien Shan, Talas Mtn. Range / Ara-Birik Valley southwest of / Kök-Say, SW of Amanbaev / 42 $22^{\prime} 54.6^{\prime \prime} \mathrm{N}, 70^{\circ} 58^{\prime} 19.9^{\prime \prime} \mathrm{E}$ / 01.VI.2013, 2150 m / leg. C. LANGE \& J. ZIEGLER” // “35.141”; CZB. New record for Kyrgyzstan.

\section{Gymnophryxe theodori (Kugler, 1968)}

Figs 5C-D, 6B, F-H

IRAN • 1 §̧; with two printed white labels: "IRAN, Fars Province / Shiraz County, Kaftarak SE of Shiraz / 10. March 2007, Sweeping / leg. M. GHeIBI, coll. J. ZIEGLER” // “32.882”; CZB. 
Kuwanimyia conspersa Townsend, 1916

TAIWAN • 1 q; with white circular label with purple ring: "LECTO- / TYPE", with printed white label: "Kankau (Formosa) / H. Sauter VII. 1912", with handwritten white label: "Dolichocolon / 4-setosum / n. sp. / N. Baranoff", with two red printed labels: "Fypus" // "Lectotypus / 1974", with two white printed and handwritten labels: "Dolichocolon / quadrisetosum Bar. / LECTOTYPE female / designated by R. W. Crosskey, 1969 / \& C. W. Sabrosky // Kuwanimyia / conspersa Tns. / B. Herting det.”; SDEI.

\section{Palesisa aureola Richter, 1974}

ISRAEL • $1 \hat{\jmath}, 1$ क; each with a printed white label: "IL [=Israel]: South District / Biq'at Sayyarim

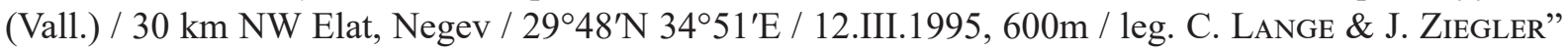
and with an additional printed white label // "13.667" resp. // "13.668"; CZB.

\section{Palesisa maculosa (Villeneuve, 1936)}

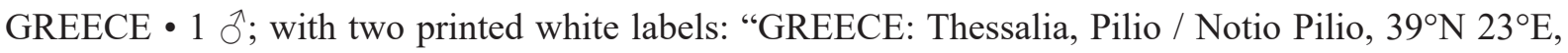
village / Platania and surrounding area / 03.VIII.2007, 0-350 m / leg. K. STANDFUSS, coll. ZIEGLER" // "36.965"; CZB. New record for Greece.

Palesisa nudioculata Villeneuve, 1929

Figs $8 \mathrm{~B}, \mathrm{E}-\mathrm{F}$

KYRGYZSTAN • 1 ठ̊; with two printed white labels: "KYRGYZSTAN, Jalal-Abad Obl. / Tien Shan, Kum Bel Mts. / Aktash west of Jangy-Bazar / Plain southeast of the village / 41 $41^{\circ} 28.1^{\prime \prime} \mathrm{N} 070^{\circ} 37^{\prime} 59.6^{\prime \prime} \mathrm{E}$ / 27.V.2013, 1380 m / leg. C. Lange \& J. Ziegler" // "35.070"; CZB. New record for Kyrgyzstan. • 2 우; same data as for preceding except "Ters Valley SW Jangy-Bazar / Besh-Aral State Reserve / 4135'30.1"N 07040'26.7"E / 26.V.2013, 1630 m / leg. C. LANGE \& J. ZiegLeR” // “34.995” resp. // “35.016”; CZB, ZMHB.

\section{Prosopodopsis appendiculata (de Meijere, 1910)}

TAIWAN • 1 \% ; with printed white label: "Anping / Formosa / H. Sauter, 1911 [with handwritten addition: "V.12"]", with printed white label: "det. Baranoff", with handwritten white label: "Prosopodopsis / fasciata Wied."; SDEI.

\section{Key (based on Tschorsnig \& Richter 1998)}

The new genus Susamyia gen. nov. can be incorporated into the modified identification key of the Palearctic tachinid genera prepared by Tschorsnig \& Richter (1998). One problem for the users of this key can be in distinguishing between upper frontal setae and upper orbital setae for which Tschorsnig \& Richter (1998) also mentioned, through the morphological description of the adult head, "One, two or more reclinate or lateroclinate upper orbital bristles present, in many genera not distinguishable from uppermost frontal bristles ...". The second problem is the intraspecific variation in the number of reclinate upper orbital bristles, which exist in Susamyia gen. nov. (cf. Figs 3, 6A, 8A with two vs Fig. 6C-E with only one) and other genera, including Palesisa Villeneuve, 1929, which usually possesses only one upper orbital seta (but in Fig. 8B with two). In case of two reclinate upper orbital setae, the anterior seta is mostly shorter than the second seta. In the description of Palesisa nudioculata, Cerretti (2010a: 276) stated "Una (raramente 2) setola orbitale reclinate superiore" and provided a photograph of the female 
head with two strong reclinate upper orbital setae (Cerretti 2010b: 124). Čepelák \& Sisojević (1974: 834) had described the male of the same species as having "1 (auch 2, vordere kürzere) oi" [one or two reclinate upper orbital setae, the anterior seta shorter]. Mesnil (1949: 101) had used this character (one or two upper orbital setae) in his key to separate Sturmiariae from Blepharellariae, and mentioned that he had encountered specimens with both 2 oi (reclinate upper orbital setae) and 1 oi among the

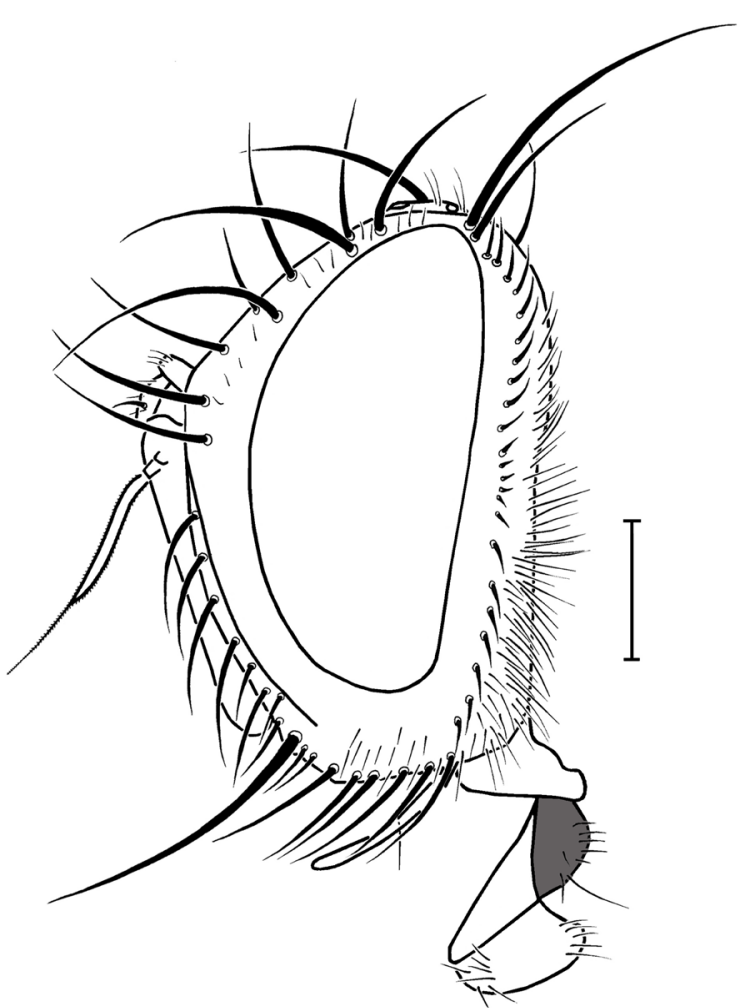

A

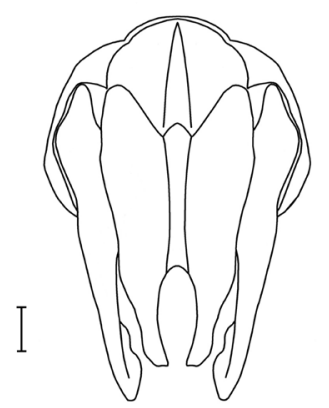

$\mathrm{C}$

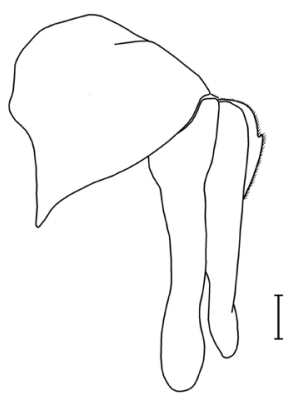

$\mathrm{D}$

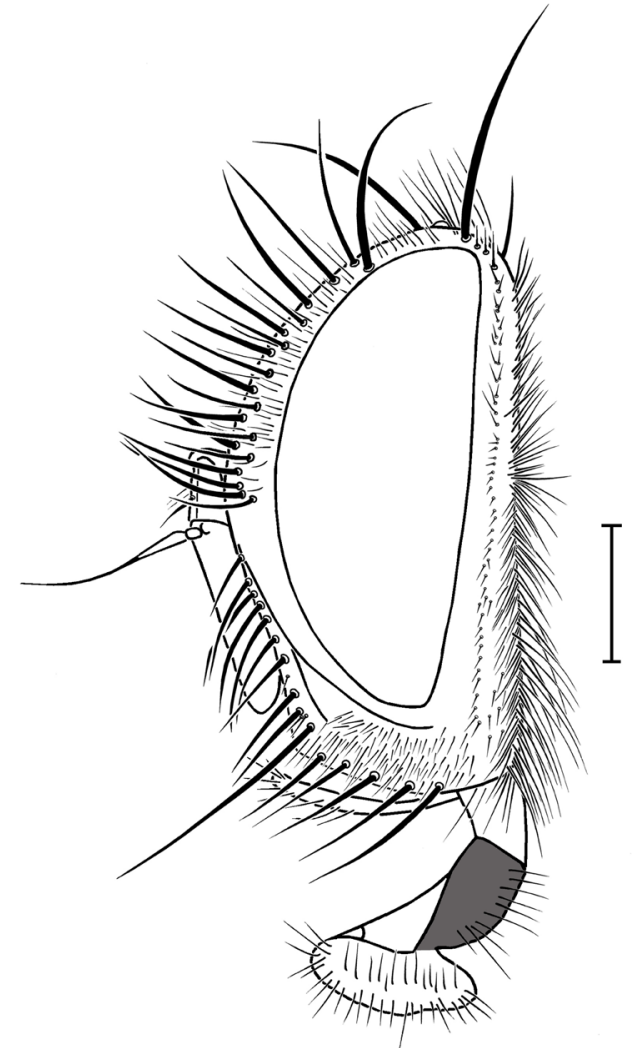

B

Fig. 8. Characters of Susamyia mira Ziegler \& Gilasian gen. et sp. nov. and Palesisa nudioculata Villeneuve, 1929. A-B. Male head, lateral view. A. Susamyia mira gen. et sp. nov., holotype, ふ̊ (HMIM). B. Palesisa nudioculata, ô (CZB). C-F. Male terminalia: epandrium, cerci and surstyli. C-D. Susamyia mira gen. et sp. nov., paratype, ふ̊ (HMIM). C. Dorsal view. D. Lateral view. E-F. Palesisa nudioculata, $\hat{\sigma}$ (CZB). E. Dorsal view. F. Lateral view. Scale bars: A-B $=0.5 \mathrm{~mm}$; $\mathrm{C}-\mathrm{F}=0.1 \mathrm{~mm}$. 
individuals of Pales pumicata (Meigen, 1824) (as Ctenophorocera). Even though the presence of 2-3 reclinate upper orbital setae has been described for the genus Gymnophryxe Villeneuve, 1922, mostly one is observed in G. theodori (Fig. 6F-H). These remarks are intended to discuss the reliability of the used characters "One single reclinate upper orbital seta" and "Two or more reclinate upper orbital setae" in the keys. Therefore, we offer here two variants of the key by Tschorsnig \& Richter (1998) to facilitate the determination of Susamyia gen. nov. in both occurrences and include the following combinations "One single reclinate upper orbital seta, if sometimes two, the uppermost stronger" and "Two reclinate upper orbital setae, the uppermost of same size or weaker, or more than two setae" in place of the original ones in the key to improve its accuracy as well.

\section{Key 1. Specimens with two or more reclinate upper orbital setae}

496. Lateral scutellar setae at least as long as half of subapical setae, but if shorter, then upper part of head with black setulae behind the postocular row. Two or three reclinate upper orbital setae present [Comment: Usually only one reclinate upper orbital seta occurs in Susamyia mira gen. et sp. nov. and Gymnophryxe theodori]

499. $\mathrm{R}_{4+5}$ setose from base to crossvein $\mathrm{r}-\mathrm{m}$ or beyond

Prosopodopsis Townsend, 1926, Suensonomyia Mesnil, 1953 and Synamphichaeta Villeneuve, 1936

- $\quad \mathrm{R}_{4+5}$ setose at most halfway to crossvein $\mathrm{r}-\mathrm{m}$

501. Legs entirely or predominantly yellow (at most tarsi black). Tegula reddish. Body length 4-7 mm.

Crapivnicia Richter, 1995, Hebia Robineau-Desvoidy, 1830 and Masistyloides Mesnil, 1963

- At least femora black or dark brown, but if (rarely) red or yellow, then body length $8 \mathrm{~mm}$ or more. Tegula usually black [Comment: The characters hardly fit in with Susamyia mira gen. et sp. nov. because of predominantly brownish-black femora and tarsi (femora orange apicoventrally), dark brownish-orange tibia, brownish orange tegula, and body length $6.3-7.5 \mathrm{~mm}]$ 503

503. Height of gena one-sixth vertical diameter of eye or more, at least as great as width of parafacial at level of base of antenna. Parafacial not or not as strongly narrowed ventrally

504. Section of M between crossveins $\mathrm{r}-\mathrm{m}$ and $\mathrm{dm}-\mathrm{cu}$ distinctly longer than section between $\mathrm{dm}-\mathrm{cu}$ and bend of $\mathrm{M}$, the latter section shorter than section between bend and apex of $\mathrm{M}$ 505

505. Arista thickened at least on basal half or more. Frons 1.1-2.5 times as wide as one eye in dorsal view. Abdominal tergites 3 and 4 with or without median discal setae 506

506. Upper part of head without black setulae behind the postocular row (rarely with a few setulae). Scutum with four pairs of postsutural dorsocentral setae. Preapical anterodorsal seta on fore tibia distinctly shorter than preapical dorsal seta (see Tschorsnig \& Richter 1998: fig. 143) .....507 (a)

507(a). Gena and sides of thorax with black setulae. Fronto-orbital plate in male with or without proclinate setae. Abdominal tergites 3 and 4 usually without median discal setae

- Gena and sides of thorax with pale setulae. Fronto-orbital plate in male without proclinate setae. Abdominal tergites 3 and 4 each with two or three pairs of median discal setae, with one pair anterior to the other

Frontina Meigen, 1838 
507(aa). Face usually 1.7-2.0 times as long as frons (Fig. 6F) [Comment: Face in G. carthaginensis (Bischof, 1900) only 1.3-1.5 times as long as frons, while frons measures 2.0-2.3 times as wide as one eye]. Frons more than 1.4 times as wide as one eye in dorsal view (Fig. 6H). Fronto-orbital plate in male with or without proclinate setae. 2-4 reclinate upper orbital setae present [Comment: Usually one reclinate upper orbital seta is present in G. theodori (Figs 6F-H)]. Apical scutellar setae inclined at $45-90^{\circ}$ to horizontal (see Tschorsnig \& Richter 1998: figs 126-127). Gena 0.30.5 times as height as vertical diameter of eye (Fig. 6F). Male terminalia: Surstylus in lateral view broader and shorter than cercus (Fig. 5D)

Gymnophryxe Villeneuve, 1922

- $\quad$ Face 1.2-1.3 times as long as frons (Fig. 6C). Frons at most 1.15-1.40 times as wide as one eye in dorsal view (Fig. 6E). Fronto-orbital plate in male with two strong proclinate setae (Fig. 6C-E) and one single reclinate upper orbital seta (sometimes a fine semi reclinate seta before, Fig. 3). Apical scutellar setae inclined at most at $30^{\circ}$ to horizontal. Gena almost 0.2 times as heigh as vertical diameter of eye (Fig. 6C). Male terminalia: Surstyli and cerci in lateral view slender; surstylus longer than cercus (Fig. 5B)

Susamyia Ziegler \& Gilasian gen. nov.

\section{Key 2. Specimens with only one reclinate upper orbital seta}

496. Upper part of head without black setulae behind the postocular row. One single reclinate upper orbital seta present (see Tschorsnig \& Richter 1998: fig. 50) [Comment: Two reclinate upper orbital setae rarely occur in the specimens of Susamyia gen. nov. (Fig. 8A) and Palesisa (Fig. 8B), while is frequently observed in the specimens of Kuwanimyia Townsend, 1916; lateral scutellar setae in Susamyia gen. nov. as strong and long as basal setae]

497. Ocellar setae reclinate. Prementum four to five times as long as its diameter. Scutellum without apical setae, but with a pair of straight nearly erect setulae on dorsal surface just anterior to apex (see Tschorsnig \& Richter 1998: fig. 123) Goniophthalmus Villeneuve, 1910

- Ocellar setae proclinate (see Tschorsnig \& Richter 1998: fig. 50). Prementum at most two times as long as its diameter. Scutellum with crossed apical bristles, without erect preapical setulae ....

498(a). Lateral scutellar setae strong, as long and strong as subapical scutellar setae. Fronto-orbital plate in both sexes with two strong proclinate setae and only a few short hair-like setulae (Figs 6C-E, $8 \mathrm{~A})$ Susamyia Ziegler \& Gilasian gen. nov.

- $\quad$ Lateral scutellar setae absent or hair-like. Fronto-orbital plate in male without proclinate setae, but with many long hair-like setulae (as in Fig. 8B) [Comment: Rare specimens of Kuwanimyia possess one proclinate upper orbital setae] 498 (aa)

498(aa). Second aristomere 1.0-2.5 times as long as its diameter. Postpedicel less than four times as long as pedicel Palesisa Villeneuve, 1929

- $\quad$ Second aristomere 2-10 times as long as its diameter. Postpedicel 4-10 times as long as pedicel in Palearctic species. For further characters see (Cerretti 2009)

..Dolichocolon Brauer \& Bergenstamm, 1889 and Kuwanimyia conspersa Townsend, 1916

\section{Discussion}

Within the subfamily Exoristinae, the tribes Goniini and Eryciini are considered morphologically and biologically close to each other and can be separated from the rest by the following characters: first postsutural supra-alar seta longer than notopleural setae; cerci not fused as syncercus; katepimeron bare or at most with 3 setulae; postpedicel not pointed apically; outer margin of lower calypter weakly convex; distiphallus not reduced; ejaculatory apodeme developed (Tschorsnig \& Herting 1994); ovolarviparous in Eryciini; micro-ovolarviparous in Goniini (Herting 1957). The species of Goniini lay their tiny 
eggs on the leaves of plants which are later swallowed by their hosts. The eggs hatch in the midgut of their host and the first instar larvae rapidly move to the body cavity to complete their development (Stireman et al. 2019). Aside from their typical microtype eggs, the male Goniini also often differ from the Eryciini in having a narrow membrane binding between sternite 6 and segment 7 and in absence of sensilla trichodea on sternite 5 (Tschorsnig 1985). The results of the molecular analyses (Fig. 9) and the microtype eggs, as well as lacking sensilla trichodea on sternite 5 and presence of a narrow membrane binding between sternite 6 and segment 7 in Susamyia gen. nov. position it reliably within Goniini.

We first used the barcode COI fragment and as in Cerretti et al. (2015) we included a large number of species of both the tribes Eryciini and Goniini. We focused mainly on Palearctic species; however, the results were similar to those of Cerretti et al. (2015): neither the tribe Eryciini nor the Goniini were monophyletic; the examined taxa were clustered irregularly without any pattern supported by morphological characters. So, the new genus Susamyia gen. nov. was not positioned reliably in the tree as the apparent phylogenetic relationships were misleading. Earlier, Tachi \& Shima (2010) used four gene markers to reconstruct the relationships of these two tribes, which resulted in a paraphyletic Eryciini and monophyletic Goniini. This finding was also supported by Stireman et al. (2019) based on 28S, CAD, MAC and MCS. We created a dataset based on four markers (16S, COI, 18S and 28S) in hope of more reliable placing of the new genus. After performing numerous analyses on several setups of the dataset, we decided to exclude the COI fragment which caused unnecessary interference and did not increase our ability to resolve phylogenetic issues in these evolutionarily young flies. Susamyia mira gen. et sp. nov. clustered very consistently in the tribe Goniini across all the analyses. In all obtained outputs, S. mira gen. et sp. nov. appeared as sister to Blepharipa sugens (Wiedemann, 1830), with this clade as sister to Frontina laeta (Meigen, 1824) (Fig. 9). Another outcome similar to above

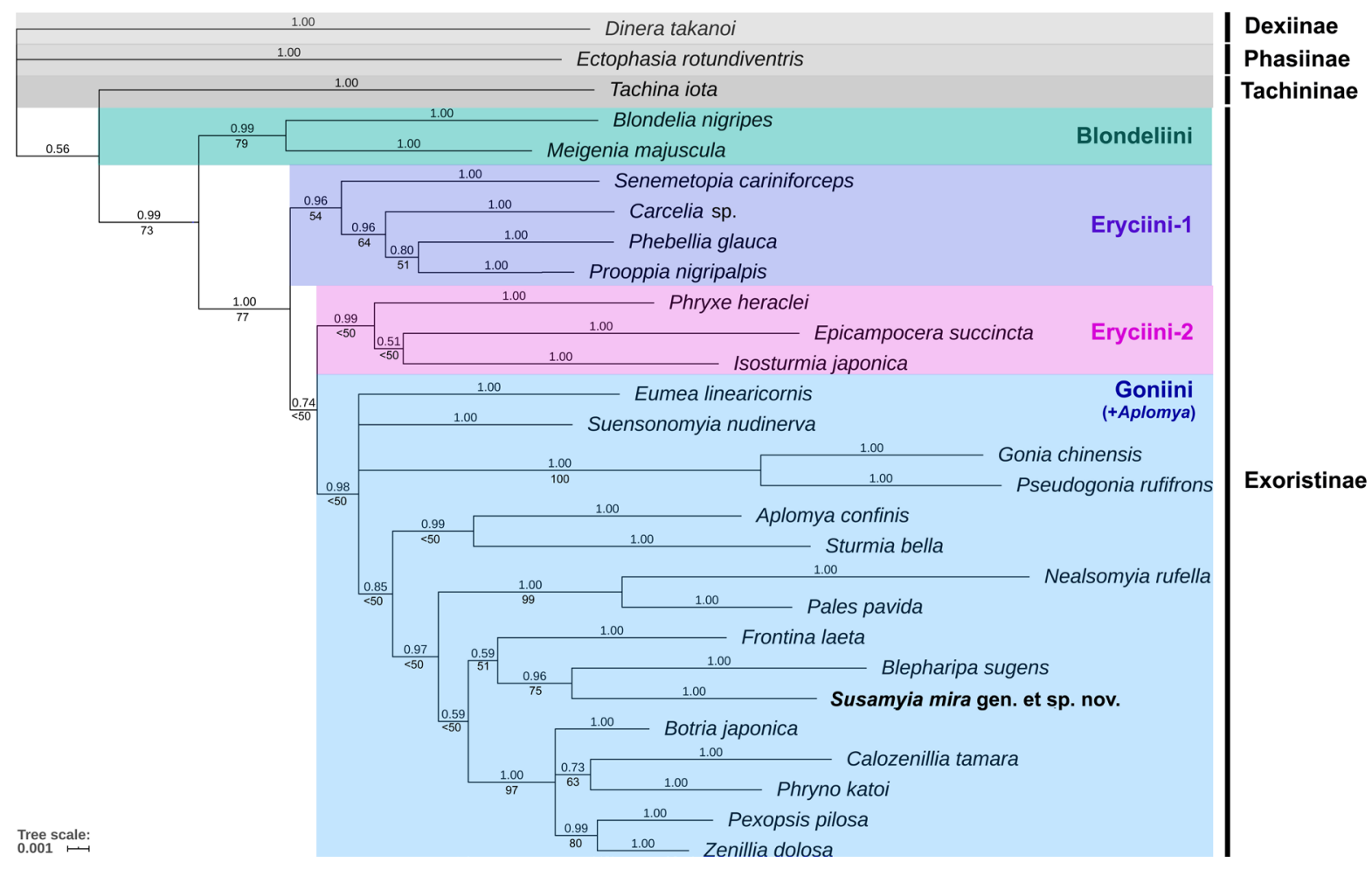

Fig. 9. Bayesian hypothesis of the phylogenetic relationships of the studied species based on 3486 characters with ML bootstrap values (posterior probabilities are shown above nodes; bootstrap values (> 50) below nodes). 
mentioned studies was the monophyletic Goniini which however also included the oviparous Aplomya confinis (Fallén, 1820), the positioning of which is rather difficult to interpret. The largest molecular analysis of Tachinidae (Stireman et al. 2019) has Aplomya in a very special position as sister to the clade Eryciini + Goniini. Unfortunately, molecular data for other taxonomically close (but very rare) genera Gymnophryxe Villeneuve, 1922, Palesisa Villeneuve, 1929 and Prosopodopsis Townsend, 1926 are not available in GenBank, and we had no access to fresh material for DNA extraction.

Cerretti et al. (2014) used 135 morphological characters from species of all subfamilies and major tribes for cladistic analyses of Tachinidae. The Goniini branched out as a monophyletic lineage based on the special character of their 'microtype' eggs. We created a morphological matrix of adult Goniini for a cladistic analysis in which we also included Susamyia gen. nov. Unfortunately, the results were not statistically significant because of the limited number of available data (trees yielded into several polytomies, data not shown). Nevertheless, Susamyia gen. nov. always formed a group together with Palesisa. The same branch also contained Blepharipa Rondani, 1856, Frontina and Pales RobineauDesvoidy, 1830 and thus approached our DNA results (Fig. 9). Cerretti et al. (2014) did not include genera Blepharipa, Gymnophryxe and Prosopodopsis in the dataset for the cladistic analysis, but genera Palesisa, Dolichocolon, Prosopea Rondani, 1861 and Pales were present and branched out together, defined by character state 71(3) "Bend of wing vein M forming a right angle or, rarely, an acute angle". This is a homoplasious apomorphy, very often evolved in parallel and found in hundreds of Palearctic genera, and therefore not that helpful for phylogenetic interpretation.

In addition to the molecular data and the external morphology of adults, we also studied the eggs hoping to find out characters of phylogenetic significance. The data are mainly derived from the previous works of Thompson (1924), Herting (1960), Gaponov (1996) and Tachi (2013). Based on the literature, only the species Pexopsis capitata (see Borisova 1961) and Pexopsis pilosa (see Shima \& Ichiki 2000) evolved unique eggs which are divided into two different parts, either with deeply dark sclerotization or pale semi-transparent and soft. In all other Goniini, the eggs are planoconvex with the dorsal chorion varying from thin and semi-transparent or pale to thick and strongly sclerotized, brown or black, like in Susamyia mira gen. et sp. nov. But the different levels of sclerotization seem to be of low phylogenetic value. As Tachi (2013) also argued, it is more likely that there was a correlation between the different levels of sclerotization and pigmentation of the chorion as well as the degree of resistance of the eggs to dehydration and other unfavorable environmental conditions.

The eggs of several species were examined using scanning electron microscopes by Salkeld (1980), Marini \& Campadelli (1994), and Gaponov (1996) who pointed out that the patterns on the dorsal chorions varied in shape and size in relation to each taxon. Gaponov $(1996,2003 a, 2003 b)$ and Tachi (2013) recognized two structural types within the Goniini of which the first type had dorsally reticulated chorion, while the second type was defined by its punctiform openings of chorion. The dorsal chorion of Susamyia gen. nov. has a system of clearly punctiform openings on the surface, but the chorion is also (weakly) reticulated, showing a combination of characters of both groups, which also appears in other species including Allophorocera arator (Aldrich, 1925) and Eumea caesar (Aldrich, 1916) (Salkeld 1980). These character states, which cannot be clearly defined, tend to be homoplastic and their value through a phylogenetic analysis proved to be ineffective.

It is important to note that the southern and southeastern regions of Iran, where the type series of Susamyia mira gen. et sp. nov. was collected, are known to serve as biogeographic crossroads for the Palearctic, Oriental and Afrotropical taxa (Abivardi 2001; Gilasian et al. 2018). For this reason, apart from the Palearctic genera, it was necessary to examine the non-Iranian genera in order to reliably establish the validity of Susamyia gen. nov. In contrast to the natural dispersal, many plant and animal species from the Nearctic have been accidentally introduced into other (climatically similar) parts of 
the world. To reliably confirm the status of the Susamyia gen. nov. as a new genus, we also studied the North American Tachinidae (Wood 1987). For example, two alien Nearctic species are known to be introduced in Europe: Trichopoda sp. (see also Ziegler \& Standfuss 2020), which is very different from Susamyia gen. nov., and Lespesia frenchii (Williston, 1889) (Herting 1960). Based on the revision of the genus Lespesia by Beneway (1963), we have concluded that its species are not very similar with Susamyia gen. nov. and moreover, they are member of the tribe Eryciini. A superficially similar genus from North America is Frontiniella Townsend, 1918, which has been revised by O'Hara (1993) and belongs into the same tribe Goniini, but its described generic diagnostic characters (on page 12) cannot be used to distinguish Frontiniella beyond the Nearctic region. These characters are widely shared by Susamyia gen. nov. and other Palearctic genera Allophorocera Hendel, 1901, Brachicheta Rondani, 1861, Ceratochaetops Mesnil, 1970, Clemelis Robineau-Desvoidy, 1863, Elodia author, year, Ocytata Gistel, 1848 and Zenillia Robineau-Desvoidy, 1830, as well as Holarctic Goniini. Based on the detailed descriptions of Frontiniella and its species (O'Hara 1993), the genera Frontiniella and Susamyia gen. nov. are separated by the following characters:

Frontiniella: Compound eye sparsely to densely covered with ommatrichia; frons in male at its narrowest point 0.6-1.1 times as wide as an eye; male without outer orbital setae; frontal row of setae hair-like toward vertex; facial ridge with setae and fine setulae of different sizes on at least half of its length; mid tibia with 1 anterodorsal seta; claw in male as long as tarsomere 5.

Susamyia gen. nov.: Compound eye bare, without ommatrichia; frons in male at its narrowest point 1.15-1.4 times as wide as an eye; both sexes with 2 strong proclinate outer orbital setae; frontal row of setae strong toward vertex; facial ridge with strongly erect setae on lower $2 / 3-3 / 4$; mid tibia with $2-3$ strong anterodorsal setae in a row with further setae of different sizes; claw in male short, 0.4 times as long as tarsomere 5 .

In light of the Afrotropical tachinid literature, basically compiled in the works of Crosskey (1984) and O'Hara \& Cerretti (2016), it is concluded that a strong morphological resemblance exists between our newly described genus and the recently described South African genus Myxophryxe Cerretti \& O'Hara, 2016, although its male postabdomen and oviposition strategy remain to be described. Therefore, it is still unclear whether Myxophryxe belongs to Eryciini or the tribe Goniini in which Susamyia gen. nov. confidently belongs to. Based on the description of Myxophryxe (O'Hara \& Cerretti 2016), the following characters can be used to make a distinction between the two genera:

Myxophryxe: Compound eye covered with thick, long ommatrichia (longest ommatrichia longer than diameter of five eye facets); proclinate orbital setae absent in male; lower facial margin warped forward and more or less visible in lateral view; male postpedicel 3.9-6.3 times as long as pedicel; gena in profile $0.25-0.50$ times as high as compound eye; upper occiput with one row of black setulae; palpus slightly clavate.

Susamyia gen. nov.: Compound eye bare, without ommatrichia; both sexes with 2 strong proclinate outer orbital setae; lower facial margin not visible in lateral view; male postpedicel 6.5-7.5 times as long as pedicel; gena in profile $0.17-0.21$ times as high as compound eye; upper occiput with only pale hair-like setulae; palpus slender, cylindrical.

Among the Oriental Tachinidae, which have been taxonomically revised by Crosskey (1976), Crosskeya Shima \& Chao, 1988, Takanomyia Mesnil, 1957 (Shima 1988) and Paravibrissina Shima, 1979 (Shima \& Tachi 2008) are the primarily known Oriental genera, which share similarities with Susamyia gen. nov. to some extent. Comparing Susamyia gen. nov. with these well-described genera provides us characters, which clearly separate it from the Oriental genera. 
The Palearctic genus Gymnophryxe is found to be highly similar to Susamyia gen. nov. from which it is separated by the following characters (see also key 1 above):

Gymnophryxe: Face 1.3-2.0 times as long as frons (Fig. 6F); frons more than 1.4 times as wide as one eye in dorsal view (Fig. $6 \mathrm{H}$ ); usually 2-4 reclinate upper orbital setae present; apical scutellar setae inclined at $45-90^{\circ}$ to horizontal; gena $0.3-0.5$ times as high as vertical diameter of eye (Fig. $6 \mathrm{~F}$ ); surstylus of male terminalia in lateral view broader and shorter than cercus (Fig. 5D).

Susamyia gen. nov.: Face 1.2-1.3 times as long as frons (Fig. 6C); frons 1.15-1.40 times as wide as one eye in dorsal view (Fig. 6E); one single reclinate upper orbital seta, sometimes with a preceding fine semireclinate seta (Fig. 3); apical scutellar setae inclined at most at $30^{\circ}$ to horizontal; gena almost 0.2 times as height as vertical diameter of eye (Fig. 6C); surstylus of male terminalia in lateral view slender; surstylus longer than cercus (Fig. 5B).

The strongest similarities occur between Susamyia gen. nov. and the genera Palesisa Villeneuve, 1929 (Palearctic) and Prosopodopsis Townsend, 1926 (Oriental, Afrotropical). Also the genera Dolichocolon Brauer \& Bergenstamm, 1889 (Old World and Australasian, see Cerretti \& Shima 2011) and Kuwanimyia Townsend, 1916 (Southeast Palearctic, Oriental, Afrotropical, see Cerretti 2009) share a number of characters with Susamyia gen. nov., including strong affinities between their male postabdomens: cerci not fused, widened, dorsoapically depressed, shorter than surstylus; surstylus straight, elongate and usually narrow (Fig. 8C-F). Additionally, they share the following characters: eye bare, facial ridge with a row of stout and erect setae over most of its length and parafacial entirely bare. All are members of the Goniini. It seems possible that this complex of morphological characters forms a monophyletic unit.

Palesisa: Fronto-orbital plate of male with 1-2 rows of more or less strong medioclinate setulae and few short and weak setulae outside frontal row (Fig. 8B); only females with two proclinate orbital setae; arista thickened at most at half of its length; lateral scutellar setae absent; epiphallus not differentiated (see also key 2 above).

Susamyia gen. nov.: Fronto-orbital plate of male with only a few hair-like black setulae outside the frontal setae (Fig. 8A); males and females with two proclinate orbital setae; arista thickened at least of two third on its length; lateral scutellar setae nearly as strong and long as basal setae; epiphallus differentiated.

Prosopodopsis: Two reclinate orbital setae, the uppermost of same size or weaker; section of wing vein $\mathrm{M}$ between crossveins $\mathrm{r}-\mathrm{m}$ and $\mathrm{dm}-\mathrm{cu}$ 1.0-1.2 times as long as section between crossvein $\mathrm{dm}-\mathrm{cu}$ and bend of $\mathrm{M}$, section of wing vein $\mathrm{M}$ between crossvein $\mathrm{dm}$-cu and bend of $\mathrm{M}$ much longer than $\mathrm{dm}$-cu; mid tibia with one strong anterodorsal seta in the middle of a row of several short setae; hind tibia with three dorsal preapical setae; epiphallus not differentiated; dorsal process of distiphallus not developed (see also key 1 above).

Susamyia gen. nov.: Usually one reclinate upper orbital seta, if sometimes two, the uppermost stronger; section of wing vein $\mathrm{M}$ between crossveins $\mathrm{r}-\mathrm{m}$ and $\mathrm{dm}-\mathrm{cu}$ 2.3-2.5 times as long as section between crossvein dm-cu and bend of $\mathrm{M}$, section of wing vein $\mathrm{M}$ between crossvein dm-cu and bend of $\mathrm{M}$ shorter than $\mathrm{dm}-\mathrm{cu}$; mid tibia with two to three strong anterodorsal setae in a row of several short setae; hind tibia with two dorsal preapical setae; epiphallus differentiated; distiphallus with developed and sclerotized dorsal process. 


\section{Acknowledgements}

Our special thanks go to the Iranian Research Institute of Plant Protection (IRIPP) and Department of Environment for funding this research. The second author thanks Dr Z. Soltész, Hungarian Natural History Museum, Budapest, Hungary, and Dr F. Menzel, Senckenberg German Entomological Institute, Müncheberg, Germany, for the loan of material in their care, and Dr B. Neuhaus, Museum of Natural History, Berlin, Germany, for the possibility to work with the microscope Axioplan 2 and for his help. We are also indebted to the reviewers for their constructive comments on the developing manuscript.

\section{References}

Abivardi S. 2001. Iranian Entomology. Vol. 1. An Introduction. Springer, Berlin.

Achterberg C. van. 2009. Can Townes type Malaise traps be improved? Some recent developments. Entomologische Berichten 69 (4): 129-135.

Belshaw R., Lopez-Vaamonde C., Degerli N. \& Quicke D.L.J. 2001. Paraphyletic taxa and taxonomic chaining: evaluating the classification of braconine wasps (Hymenoptera: Braconidae) using 28S D2-3 rDNA sequences and morphological characters. Biological Journal of the Linnean Society 73: 411-424. https://doi.org/10.1111/j.1095-8312.2001.tb01370.x

Beneway D.F. 1963. A revision of the flies of the genus Lespesia (= Archaetoneura) in North America (Diptera: Tachinidae). University of Kansas Science Bulletin 44: 627-686.

Borisova K.B. 1961. Takhina Pexopsis capitata Mesnil (Diptera, Larvaevoridae) parasit dal'nevostochnogo Ijun'skogo Khrushha Holotrichia diomphalia Bates (Coleoptera, Scarabaeidae). [Pexopsis capitata Mesn. (Diptera, Larvaevoridae), parasite of Holotrichia diomphalia Bates (Coleoptera, Scarabaeidae)]. Entomologicheskoe obozrenie 40 (3): 584-594. [In Russian with English summary.]

Čepelák J. \& Sisojević P. 1974. Beschreibung des unbekannten Weibchens Palesisa nudioculata Villeneuve, 1929 (Dipt. Tachinidae) aus Macedonien. Biológia (Bratislava) 29: 11: 831-836.

Cerretti P. 2009. A review of the genus Kuwanimyia Townsend (Diptera: Tachinidae), with taxonomic remarks on related genera. African Entomology 17 (1): 51-63. https://doi.org/10.4001/003.017.0107

Cerretti P. 2010a. I tachinidi della fauna italiana (Diptera Tachinidae) con chiave interattiva dei generi ovest-paleartici. Vol. 1. Cierre edizioni, Verona.

Cerretti P. 2010b. I tachinidi della fauna italiana (Diptera Tachinidae) con chiave interattiva dei generi ovest-paleartici. Vol. 2. Cierre edizioni, Verona.

Cerretti P. \& Shima H. 2011. World revision of Dolichocolon Brauer \& Bergenstamm (Diptera: Tachinidae: Exoristinae: Goniini). Zoological Journal of the Linnean Society 162 (3): 544-584. https://doi.org/10.1111/j.1096-3642.2010.00689.x

Cerretti P., O’Hara J.E., Wood D.M., Shima H., Inclan D.J. \& Stireman III J.O. 2014. Signal through the noise? Phylogeny of the Tachinidae (Diptera) as inferred from morphological evidence. Systematic Entomology 39: 335-353. https://doi.org/10.1111/syen.12062

Cerretti P., O’Hara J.E., Winkler I.S., Lo Giudice G. \& Stireman III J.O. 2015. Two tribes hidden in one genus: the case of Agaedioxenis Villeneuve (Diptera: Tachinidae: Exoristinae). Organisms, Diversity and Evolution 15: 489-512. https://doi.org/10.1007/s13127-015-0211-0

Crosskey R.W. 1976. A taxonomic conspectus of the Tachinidae (Diptera) of the Oriental Region. Bulletin of the British Museum (Natural History). Entomology Supplement 26: 1-357.

Crosskey R.W. 1984. Annotated keys to the genera of Tachinidae (Diptera) found in tropical and southern Africa. Annals of the Natal Museum 26 (1): 189-237. 
GILASIAN E. et al., Susamyia mira, a new tachinid genus and species from Iran

Evenhuis N.L. 2020. The insect and spider collections of the world website.

Available from http://hbs.bishopmuseum.org/codens/ [accessed 9 Mar. 2020].

Gaponov S.P. 1996. Morfologija poverkhnosti mikrotipicheskikh jaic palearkticheskikh Goniini (Diptera, Tachinidae). [Survey of microtype eggs in Palearctic Goniini (Diptera, Tachinidae)]. Zoologicheskii zhurnal (Moscow) 75 (5): 713-725. [In Russian with English summary.]

Gaponov S.P. 2003a. Morfologija jaic takhin (Diptera, Tachinidae). Voronezh State University, Voronezh. [In Russian.]

Gaponov S.P. 2003b. Morfologija i ehvoljucionnye preobrasovanija jaic dvukrylykh (Diptera). Voronezh State University, Voronezh. [In Russian.]

Gilasian E., Ziegler J. \& Parchami-Araghi M. 2016a. Interim report on the project to study the tachinid fauna of Khuzestan, Iran. The Tachinid Times 29: 11-12.

Gilasian E., Ziegler J. \& Parchami-Araghi M. 2016b. A review of the genus Minthodes Brauer \& Bergenstamm (Diptera: Tachinidae) in Iran, with the description of a new species. Zootaxa 4173 (2): 125-136. https://doi.org/10.11646/zootaxa.4173.2.3

Gilasian E., Ziegler J. \& Parchami-Araghi M. 2018. Review of the genus Trichactia Stein (Diptera: Tachinidae) in the Palearctic region, with the description of a new species from Iran and eastern Mediterranean area. Zootaxa 4526 (2): 207-220. https://doi.org/10.11646/zootaxa.4526.2.6

Gilasian E., Ziegler J. \& Parchami-Araghi M. 2019. Review of the genus Bampura Tschorsnig (Dipt.: Tachinidae) with the description of a new species from southwestern Iran. Zootaxa 4585 (1): 41-58. https://doi.org/10.11646/zootaxa.4585.1.3

Herting B. 1957. Das weibliche Postabdomen der calyptraten Fliegen (Diptera) und sein Merkmalswert für die Systematik der Gruppe. Zeitschrift für Morphologie und Ökologie der Tiere 45: 429-461. https://doi.org/10.1007/BF00389872

Herting B. 1960. Biologie der westpaläarktischen Raupenfliegen (Dipt., Tachinidae). Monographien zur angewandten Entomologie16: 1-188.

Huelsenbeck J.P. \& Ronquist F.R. 2001. MrBayes: Bayesian inference of phylogeny. Biometrics 17: 754-755. https://doi.org/10.1093/bioinformatics/17.8.754

Katana A., Kwiatowski J., Spalik K., Zakryś B., Szalacha E. \& Szymańska H. 2001. Phylogenetic position of Koliella (Chlorophyta) as inferred from nuclear and chloroplast small subunit rDNA. Journal of Phycology 37: 443-451. https://doi.org/10.1046/j.1529-8817.2001.037003443.x

Katoh K. \& Standley D.M. 2013. MAFFT multiple sequence alignment software version 7: improvements in performance and usability. Molecular Biology and Evolution 30: 772-780.

https://doi.org/10.1093/molbev/mst010

Letunić I. \& Bork P. 2016. Interactive tree of life (iTOL) v3: an online tool for the display and annotation of phylogenetic and other trees. Nucleic Acids Research 44: 242-245.

https://doi.org/10.1093/nar/gkw290

Marini M. \& Campadelli G. 1994. Ootaxonomy of Goniini (Diptera, Tachinidae) with microtype eggs. Bollettino di Zoologia 61: 271-283. https://doi.org/10.1080/11250009409355894

Merz B. \& Haenni J.-P. 2000. Morphology and terminology of adult Diptera (other than terminalia). In: Papp L. \& Darvas B. (eds) Contributions to a Manual of Palearctic Diptera (with Special Reference to Flies of Economic Importance). Vol. 1. General and Applied Dipterology: 21-51. Science Herald, Budapest. 
Mesnil L.P. 1949. Larvaevorinae (Tachininae) [Lieferung 161]. In: Lindner E. (ed.) Die Fliegen der palaearktischen Region: 49-104. E. Schweizerbart'sche Verlagsbuchhandlung, Stuttgart.

Miller M.A., Pfeiffer W. \& Schwartz T. 2010. Creating the CIPRES Science Gateway for inference of large phylogenetic trees. Proceedings of the Gateway Computing Environments Workshop (GCE): 1-8. New Orleans, LA. https://doi.org/10.1109/GCE.2010.5676129

Nylander J.A.A. 2004. MrModeltest v2.2. Program distributed by the author. Evolutionary Biology Centre, Uppsala University, Uppsala.

O'Hara J.E. 1993. Revision of the species of Frontiniella Townsend (Diptera: Tachinidae). Canadian Entomologist 125: 11-45. https://doi.org/10.4039/Ent12511-1

O'Hara J.E. \& Cerretti P. 2016. Annotated catalogue of the Tachinidae (Insecta, Diptera) of the Afrotropical Region, with the description of seven new genera. ZooKeys 575: 1-344.

https://doi.org/10.3897/zookeys.575.6072

O’Hara J.E., Henderson S.J. \& Wood D.M. 2020. Preliminary checklist of the Tachinidae (Diptera) of the world. Version 2.1. Available from

http://www.nadsdiptera.org/Tach/WorldTachs/Checklist/Tachchlist_ver2.1.pdf [accessed 15 Dec. 2020].

Roháček J., Tóthová A. \& Vaňhara J. 2009. Phylogeny and affiliation of European Anthomyzidae (Diptera) based on mitochondrial 12S and 16S rRNA. Zootaxa 2054: 49-58.

https://doi.org/10.11646/zootaxa.2054.1.3

Salkeld E.H. 1980. Microtype eggs of some Tachinidae (Diptera). Canadian Entomologist 112: 51-83. https://doi.org/10.4039/Ent11251-1

Shima H. 1988. Some remarkable new species of Tachinidae (Diptera) from Japan and the IndoAustralian Region. Bulletin of the Kitakyushu Museum of Natural History 8: 1-37.

Shima H. \& Ichiki R. 2000. A micro-oviparous tachinid Pexopsis pilosa (Diptera: Tachinidae) parasitic on scarabaeid beetles in Japan. XXI International Congress of Entomology, Brazil, Abstract I: 417.

Shima H. \& Tachi T. 2008. New species of the genus Paravibrissina Shima (Diptera: Tachinidae) from Southeast Asia and South Pacific. Zootaxa 1870: 43-60. https://doi.org/10.11646/zootaxa.1870.1.3

Sinclair B.J. 2000. Morphology and terminology of Diptera male terminalia. In: Papp L. \& Darvas B. (eds) Contributions to a Manual of Palearctic Diptera (with Special Reference to Flies of Economic Importance). Vol. 1. General and Applied Dipterology: 53-74. Science Herald, Budapest.

Stireman III J.O., Cerretti P., O’Hara J.E., Blaschke J.D. \& Moulton J.K. 2019. Molecular phylogeny and evolution of world Tachinidae (Diptera). Molecular Phylogenetics and Evolution 139: 1-19. https://doi.org/10.1016/j.ympev.2018.12.002

Stuckenberg B.R. 1999. Antennal evolution in the Brachycera (Diptera), with a reassessment of terminology relating to the flagellum. Studia dipterologica 6: 33-48.

Tachi T. \& Shima H. 2010. Molecular phylogeny of the subfamily Exoristinae (Diptera, Tachinidae), with discussions on the evolutionary history of the female oviposition strategy. Systematic Entomology 35: 148-163. https://doi.org/10.1111/j.1365-3113.2009.00497.x

Tachi T. 2013. Systematic study of the genera Phryno Robineau-Desvoidy and Botria Rondani in the Palearctic Region, with discussions of their phylogenetic positions (Diptera, Tachinidae). Zootaxa 3609 (4): 361-391. https://doi.org/10.11646/zootaxa.3609.4.1

Thompson W.R. 1924. Les larves primaires des Tachinaires à oeufs microtypes. Annales de Parasitologie humaine et comparée (Paris) 2: 185-201, 279-306. https://doi.org/10.1051/parasite/1924023185, https://doi.org/10.1051/parasite/1924024279 
Tschorsnig H.-P. 1985. Taxonomie forstlich wichtiger Parasiten: Untersuchungen zur Struktur des männlichen Postabdomens der Raupenfliegen (Diptera, Tachinidae). Stuttgarter Beiträge zur Naturkunde, Serie A (Biologie) 383: 1-137.

Tschorsnig H.-P. \& Herting B. 1994. Die Raupenfliegen (Diptera: Tachinidae) Mitteleuropas: Bestimmungstabellen und Angaben zur Verbreitung und Ökologie der einzelnen Arten. Stuttgarter Beiträge zur Naturkunde, Serie A (Biologie) 506: 1-170.

Tschorsnig H.-P. \& Richter V.A. 1998. Family Tachinidae. In: Papp L. \& Darvas B. (eds) Contributions to a manual of Palearctic Diptera (with special reference to flies of economic importance). Vol. 3. Higher Brachycera: 691-827. Science Herald, Budapest.

Wood D.M. 1987. Tachinidae. In: McAlpine J.F., Peterson B.V., Shewell G.E., Teskey H.J., Vockeroth J.R. \& Wood D.M. (eds) Manual of Nearctic Diptera. Vol. 2: 1193-1269. Agriculture Canada Monograph 28: i-vi, 675-1332.

Ziegler J. \& Standfuss K. 2020. Raupenfliegen (Diptera, Tachinidae) aus der Umgebung von Platania (Halbinsel Pilion, Griechenland). Studia dipterologica 23 (2) (2016): 237-258.

Zwickl D.J. 2006. Genetic Algorithm Approaches for the Phylogenetic Analysis of Large Biological Sequence Datasets Under the Maximum Likelihood CSriterion. PhD dissertation, University of Texas at Austin, Austin, Texas.

Manuscript received: 17 October 2020

Manuscript accepted: 9 February 2021

Published on: 27 April 2021

Topic editor: Nesrine Akkari

Section editor: Torbjørn Ekrem

Desk editor: Radka Rosenbaumová

Printed versions of all papers are also deposited in the libraries of the institutes that are members of the EJT consortium: Muséum national d'histoire naturelle, Paris, France; Meise Botanic Garden, Belgium; Royal Museum for Central Africa, Tervuren, Belgium; Royal Belgian Institute of Natural Sciences, Brussels, Belgium; Natural History Museum of Denmark, Copenhagen, Denmark; Naturalis Biodiversity Center, Leiden, the Netherlands; Museo Nacional de Ciencias Naturales-CSIC, Madrid, Spain; Real Jardín Botánico de Madrid CSIC, Spain; Zoological Research Museum Alexander Koenig, Bonn, Germany; National Museum, Prague, Czech Republic. 